\title{
REGULATORY NETWORKS IN BILE SALT AND FERRIC IRON INDUCED RESISTANCE OF ENTEROHEMORRHAGIC ESCHERICHIA COLI TO CATIONIC ANTIMICROBIAL PEPTIDES
}

By

\section{Chhatra Kunwar}

M. Sc. Biochemistry, University of Rajasthan, 2007

\author{
A thesis \\ presented to Ryerson University \\ in partial fulfillment of the \\ requirements for the degree of \\ Master of Science \\ in the program of Molecular Science
}

Toronto, Canada, 2018

CChhatra Kunwar, 2018 


\section{AUTHOR'S DECLARATION FOR ELECTRONIC SUBMISSION OF A THESIS}

I hereby declare that I am sole author of this thesis. This is a true copy of the thesis, including any required final revisions, as accepted by my examiners.

I authorize Ryerson University to lend this thesis to other institutions or individuals for the purpose of scholarly research.

I further authorize Ryerson University to reproduce this thesis by photocopying or by other means, in total or in part, at the request of other institutions or individuals for the purpose of scholarly research.

I understand that my thesis may be made electronically available to the public. 


\title{
Regulatory Networks in Bile Salt and Ferric Iron Induced Resistance of Enterohemorrhagic Escherichia coli to Cationic Antimicrobial Peptides
}

\author{
Chhatra Bahadur Kunwar \\ MSc, Molecular Science, Ryerson University, Toronto, 2018
}

\begin{abstract}
Enterohemorrhagic Escherichia coli (EHEC) possess the ability to respond to its surroundings though two-component systems. We hypothesized that gastrointestinal cues such as bile, iron and $\mathrm{pH}$ promote EHEC resistance to cationic antimicrobial peptides (CAMPs) during infection. Killing assays reveal that exposure to low $\mathrm{pH}$, high iron or bile salt mixture results in increased CAMP resistance that is dependent on $p m r B$ but independent of $p m r D$. Low $\mathrm{Mg}^{+2}$-induced CAMP resistance is dependent on $p m r D$. $p m r D$ promoter analysis indicate that EHEC responds to PhoPQ-inducing conditions by increasing $p m r D$ expression. However, $p m r D$ expression is repressed upon exposure to low acid, bile salt mix and iron. This study suggests that a complex interplay of PhoPQ, PmrAB and PmrD is involved in EHEC's response to various microenvironmental signals and in the promotion of EHEC's resistance to CAMPS. The results also provide intriguing evidence of both cooperation and redundancy in the mediation of CAMP resistance by these molecular players.
\end{abstract}




\section{Acknowledgements}

This work would have been impossible without the precious advice and support of many people.

First and foremost, I would like to thank my supervisor Dr. Debora Foster for providing me the opportunity to work in her lab and for excellent guidance, encouragement and support throughout this work.

I am very grateful to the members of my supervisor committee, Dr. Joseph B McPhee and Dr. Costin Antonescu for their valuable guidance, suggestions and discussions.

To past and present members of the Foster lab, thank you all for your constructive criticism and support inside and outside the lab which were critical to the completion of this research. A special thanks to Tracy, AJ, Veronica, Alyssa and Sarah for technical help and useful discussions.

Finally, I acknowledge financial support from Department of Chemistry and Biology, the Faculty of Science, and the Natural Sciences and Engineering Research Council of Canada. 


\section{DEDICATION}

In memory of my mother, Bishnu 


\section{Table of Contents}

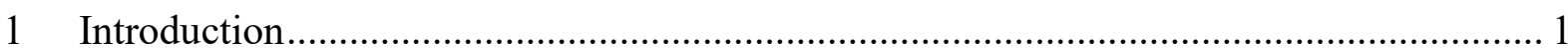

1.1 Overview of enterohemorrhagic Escherichia coli (EHEC) ................................... 1

1.2 EHEC outbreaks and public health significance ............................................... 2

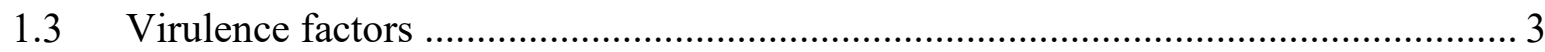

1.4 Host factors and modulation of virulence ....................................................... 5

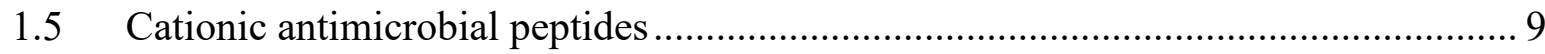

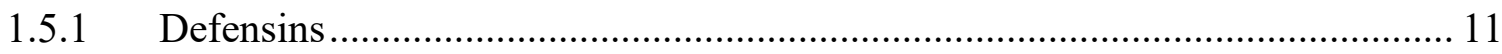

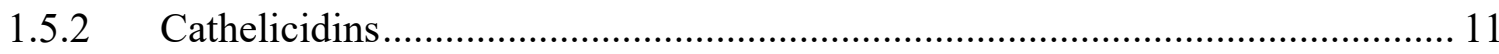

1.6 Two-component regulatory systems and cross talk ........................................ 14

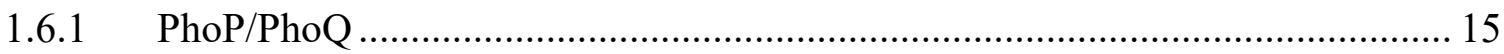

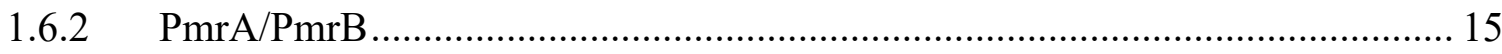

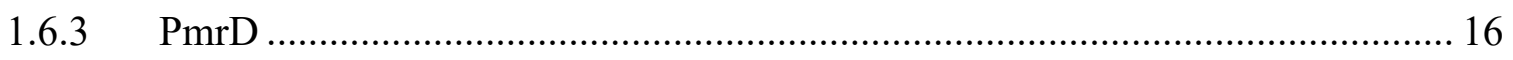

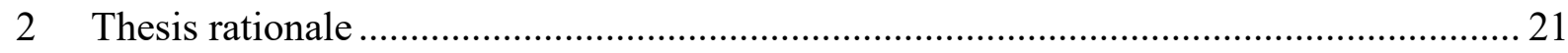

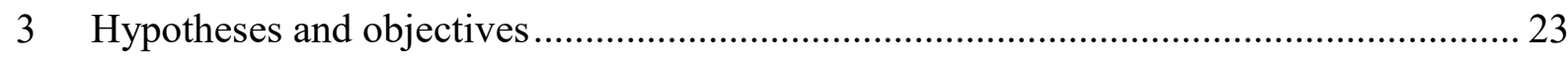

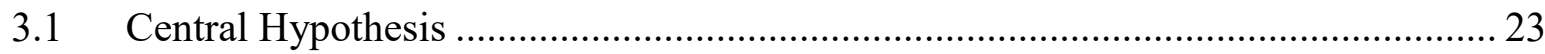

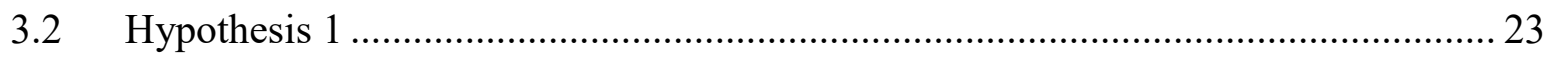

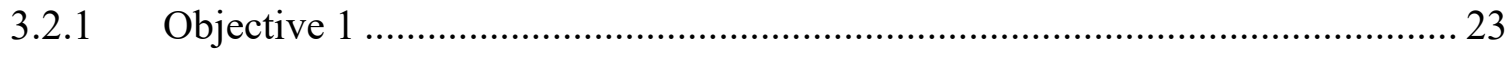




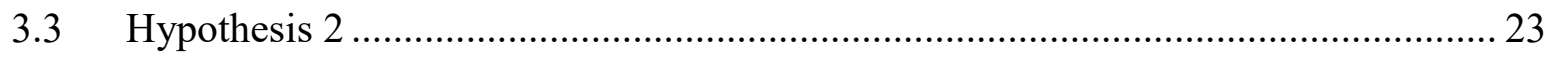

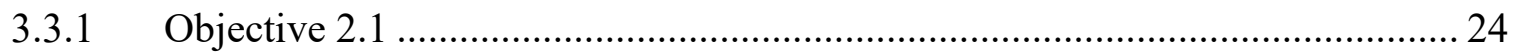

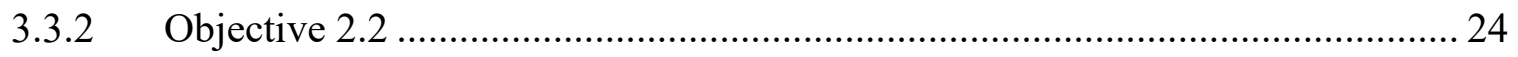

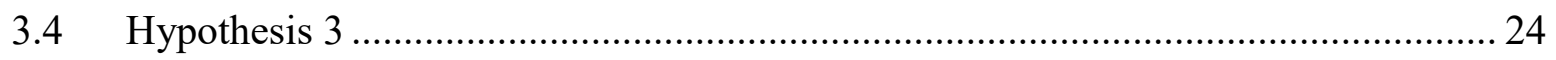

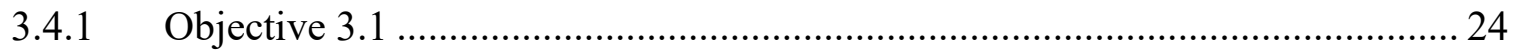

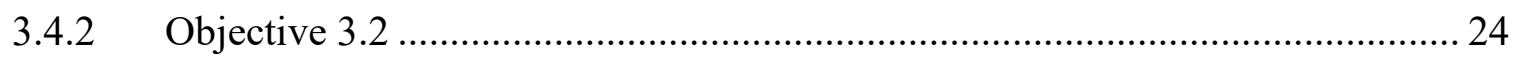

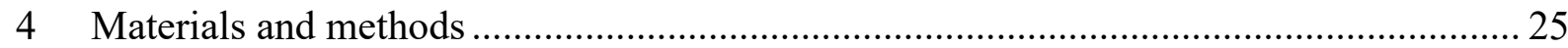

4.1 Bacterial strains, growth conditions and reagents ............................................. 25

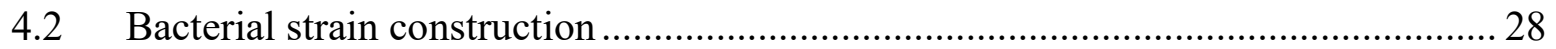

4.2.1 Construction of $p m r D$ and $p h o P$ isogenic mutants ................................... 28

4.2.2 Construction of $\Delta p m r D$ complementation strain ....................................... 28

4.2.3 Construction of reporter plasmid ............................................................ 29

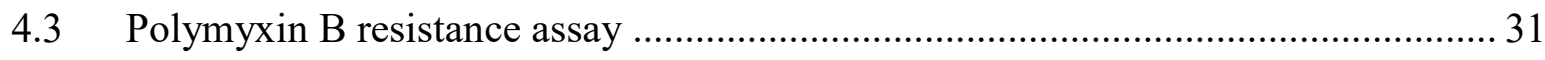

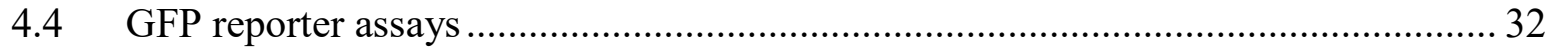

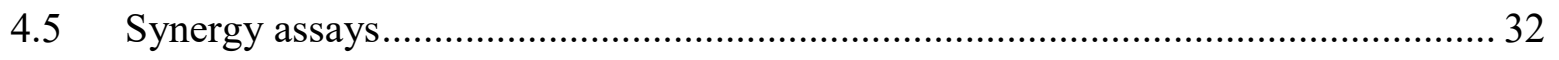

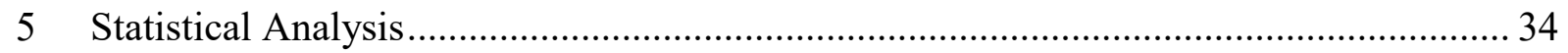

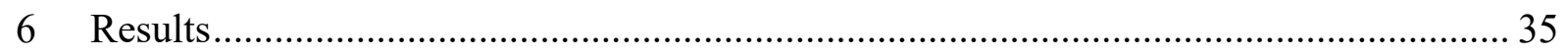

6.1 Low $\mathrm{Mg}^{+2}$ and mild acid signal promotes PMB resistance in EHEC through specific

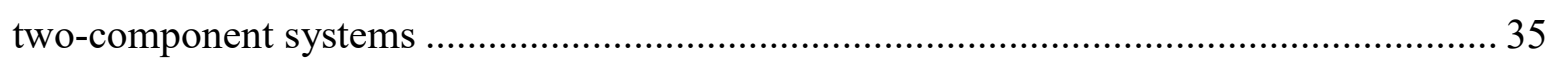


6.2 Exposure to physiological relevant bile salt mixture induces PMB resistance in EHEC

6.3 Exposure to high iron induces PMB resistance in EHEC 86-24 ........................... 39

6.4 BSM and $\mathrm{Fe}^{3+}$-induced PMB resistance is dose-dependent ................................ 41

6.5 $\mathrm{BSM}$ and $\mathrm{Fe}^{3+}$ have no additive effect on PMB resistance ................................. 42

6.6 $\mathrm{BSM}$ and $\mathrm{Fe}^{3+}$ signal activate PMB resistance in a PmrB dependent fashion ......... 44

6.7 The activity of the $p m r D$ promoter is influenced by numerous signals ................. 46

6.7.1 The $p m r D$ promoter is highly active under low Magnesium .......................... 46

6.7.2 The pmrD promoter activity repressed by BSM and $\mathrm{Fe}^{3+} \ldots \ldots \ldots \ldots \ldots \ldots \ldots \ldots . . . . . . . . . . . . . . .47$

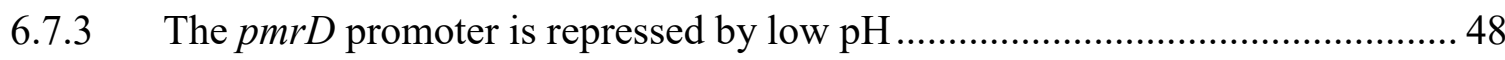

6.8 No interaction exists between BSM and PMB ….............................................. 50

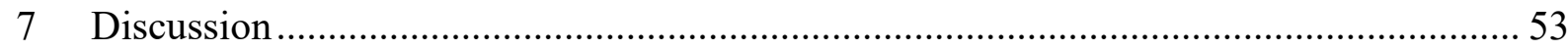

8 Summary and significance

9 Model of regulation of PMB resistance in EHEC 86-24 ............................................ 64

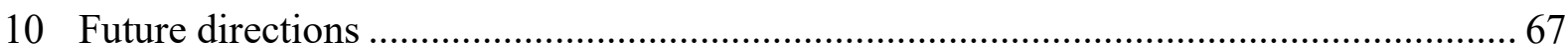




\section{List of Tables}

Table 1 Major human cationic antimicrobial peptides: defensins and cathelicidins .............. 10

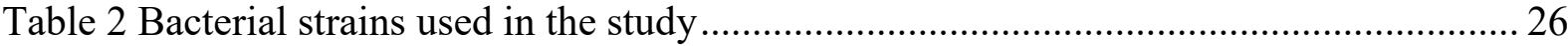

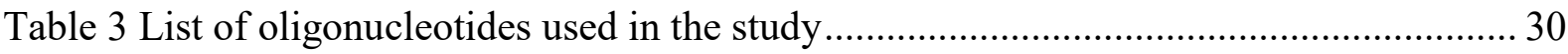

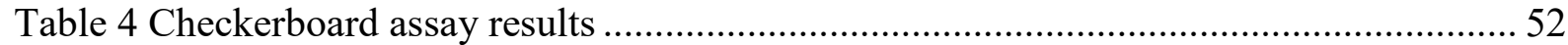




\section{List of Figures}

Figure 1 Structures of common primary and secondary bile acids. .................................... 7

Figure 2 Proposed mechanisms of action of cationic antimicrobial peptides ...................... 13

Figure 3 PhoP/PhoQ and PmrA/PmrB two-component systems in S. typhimurium and E. coli.

Figure 4 Low $\mathrm{Mg}^{+2}$ and mild acid both promote PMB resistance in EHEC 86-24 differently 37

Figure 5 Bile salt mixture treatment increases the PMB resistance in WT and $p m r D$ mutant under high $\mathrm{Mg}^{+2}$ at neutral $\mathrm{pH}$ but not under low $\mathrm{Mg}^{+2}$ at neutral $\mathrm{pH}$................................ 39

Figure 6 Iron-induced PMB resistance is independent of PmrD

Figure 7 Pre-treatment of WT and pmrD mutants with increasing concentration of BSM and $\mathrm{Fe}^{3+}$ causes correspondingly increased survival3.

Figure 8 Combined pre-treatment with $0.8 \% \mathrm{BSM}$ and $50 \mu \mathrm{M} \mathrm{Fe}^{3+}$ signals has no additive effect on survival rate

Figure 9 Survival rate after PMB treatment of EHEC WT, $\Delta p m r B$ and $\Delta p h o P$..... 45

Figure 10 pmrD promoter activity monitored under low $\mathrm{Mg}^{+2}$ at neutral $\mathrm{pH}$ and measured the effect of signals such as low $\mathrm{pH}, 1.5 \% \mathrm{BSM}$ and high $\mathrm{Fe}^{3+}$. 50

Figure 11 Model of regulation of PMB resistance under low $\mathrm{Mg}^{2+}$ in EHEC 86-24............. 64

Figure 12 Model of regulation of PMB resistance under high $\mathrm{Mg}^{2+}$ and neutral $\mathrm{pH}$ in EHEC 8624 


\section{List of Abbreviations}

\begin{tabular}{|c|c|}
\hline AmpR & Ampicillin Resistance \\
\hline Ara4N & 4-Amino-4-deoxy-L-arabinose \\
\hline ArnT & enzyme that modifies lipid A with aminoarabinose \\
\hline BSM & Bile Salt Mixture \\
\hline CAMPs & Cationic Antimicrobial Peptides \\
\hline CFU & Colony Forming Units \\
\hline EHEC & Enterohaemorrhagic Escherichia coli \\
\hline FIC & Fractional inhibitory concentration \\
\hline HBD & human Beta-Defensin \\
\hline hCAP-18 & human Cationic Antimicrobial Protein, $18 \mathrm{kDa}$ \\
\hline HD-5 & Human Defensin-5 \\
\hline HNP & Human Neutrophil Peptide \\
\hline HUS & Hemolytic Uremic Syndrome \\
\hline IM & Inner Membrane \\
\hline KanR & Kanamycin Resistant \\
\hline L-Ara4N & 4-amino-4-deoxy-L-arabinose \\
\hline LB & Lysogeny Broth \\
\hline LEE & Locus of enterocyte effacement \\
\hline LPS & Lipopolysaccharide \\
\hline $\mathrm{OD}_{600}$ & Optical Density $600 \mathrm{~nm}$ \\
\hline $\mathrm{OM}$ & Outer Membrane \\
\hline
\end{tabular}


PBS Phosphate Buffered Saline

PCR Polymerase Chain Reaction

PEtN Phosphoethanolamine

PMB Polymyxin B

PmrAB Two-component regulatory system (response and sensor regulator)

PmrD Polymyxin resistant protein D

rpm revolutions per minute

Stx Shiga toxin

Stx1 Shiga toxin 1

Stx2 Shiga toxin 2

T3SS Type III secretion system

TCRS Two-Component Regulatory System

Tir Translocated intimin receptor

TLR Toll-Like Receptor

VT Verotoxin

WT Wild-Type

X-gal 5-bromo-4-chloro-3-indolyl- $\beta$-D-galactopyranoside 


\section{Introduction}

\subsection{Overview of enterohemorrhagic Escherichia coli (EHEC)}

Enterohemorrhagic Escherichia coli (EHEC) O157:H7 is a member of the large family of Enterobacteriaceae. It is a gram-negative, non-spore-forming, rod-shaped bacterium. Escherichia coli exists as part of the natural flora of gastrointestinal tract of warm-blooded animals, including humans and considered non-pathogenic. However, there are specific strains of $E$ coli that are associated with both intestinal and extraintestinal diseases. The strains that are associated with human diarrheal diseases are usually classified into five pathotypes: enterohemorrhagic E. coli (EHEC), enterotoxigenic E. coli (ETEC), enteropathogenic E. coli (EPEC), enteroaggregative E. coli (EAEC), enteroinvasive E. coli (EIEC) (Croxen et al. 2013). Among these classes, EHEC is usually the most important pathogen from public health point of view (Lim et al. 2010).

Escherichia coli $\mathrm{O} 157: \mathrm{H7}$ is the predominant serotype representing the EHEC group. Serotype identification is based on surface structures such as the somatic antigen $\mathrm{O}$ and flagellar antigen H. EHEC O157:H7 is the cause of foodborne outbreaks around the world, mainly affecting developed parts of the world such as USA, Canada and Europe. The other serotypes that are common in food borne outbreaks after $\mathrm{O} 157$ are $\mathrm{O} 26, \mathrm{O} 111, \mathrm{O} 103$, O121, O45 and O145 (Smith et al. 2014). 
EHEC O157:H7 was first identified as a human pathogen in 1982 after food-borne outbreak investigation in USA. This pathogen is a major concern for scientists and healthcare professionals, due to its low infectious dose (10-100 microorganisms) (Kiranmayi et al. 2010) and high capacity to cause severe systemic complications such as hemorrhagic colitis (HC) and hemolytic uremic syndrome (HUS) (Page and Liles 2013). Treatment options for this infection are limited to supportive care to control the symptoms. Because of the risk of release of Shiga toxin, a potent cytotoxin of EHEC by the use of conventional antibiotics, effective intervention options are therefore very limited (Safdar et al. 2002).

\subsection{EHEC outbreaks and public health significance}

Cattle are the primary reservoir of EHEC. When shed from the reservoir, they can survive for a month in the environment such as food and water (Mayer et al. 2012). EHEC outbreaks occur in different parts of the world including North America, Europe and Asia, sometimes with simple diarrhea but occasionally involving HUS and sometimes leading to death.

There are multiple ways by which humans can contract EHEC infection. The majority of human infections have been associated to consumption of meat and raw food as evidenced by outbreak investigations. The consumption of contaminated food or water is the main route of transmission of EHEC infection. Both $\mathrm{O} 157$ and non-O157 E. coli cause large numbers of cases in the United States and Canada (Crim et al., 2013, Sockett et al., 2014). 
The Centers for Disease Control and Prevention estimates that over 265,000 cases of foodborne illnesses due to E. coli $\mathrm{O} 157: \mathrm{H} 7$ occurs every year in the United States alone resulting in more than 3,600 hospitalizations and 30 deaths (CDC 2016). Some of the large foodborne outbreaks like one in Germany where entirely new strain, O104:H4 with more incidence of HUS emerged, makes this pathogen even more dangerous foodborne pathogen. Furthermore, the economic burden due to E. coli $\mathrm{O} 157: \mathrm{H} 7$ associated infections is very large. The total estimate from medical expenses and productivity is estimated to be \$405 million (Kiranmayi et al. 2010). According to the recent data, the annual cost associated with E. coli $\mathrm{O} 157: \mathrm{H} 7$ illness in Canada alone is estimated to be over 377 million dollars (Sockett et al. 2014). The effects are not only confined in human health and medical costs. The food industry, particularly the meat and vegetables production and distribution system may suffer huge economic losses from recalls or removal of E. coli O157:H7contaminated food items from the markets. With the large number of outbreaks both locally and globally and the high costs associated with the EHEC-related illnesses, there is a need to invest in these fields. Since foodborne EHEC outbreaks continue to be a problem worldwide, improved intervention in the food industry and improved treatment methods are essential.

\subsection{Virulence factors}

EHEC is equipped with multiple virulence factors that enables it to become a successful enteric pathogen in human. Two of the most important virulence factors are the Shiga 
toxins (Stx). Besides Stx, EHEC harbors the highly conserved locus of enterocyte effacement (LEE) pathogenicity island, which encodes a number of proteins, including type 3 secretion system (T3SS), the primary adhesin intimin, the major adhesins and other effector proteins required for initiating pathogenesis.

EHEC is a non-invasive mucosal pathogen which possesses a unique mechanism of colonization and pathogenesis. The main virulence factor that contributes to the initiation of colonization is the main adhesin, intimin. When bacteria transit though intestine, intimin mediates the attachment to human colonic epithelial cells. After colonization and effector protein secretion, EHEC destroy the brush border microvilli and induce cytoskeletal rearrangements underneath itself (Nguyen and Sperandio 2012). This results in characteristic lesions known as attaching and effacing $(\mathrm{A} / \mathrm{E})$ lesions which are a classic feature of EHEC and EPEC infection.

Shiga-toxins are potent cytotoxins that can specifically interact with their receptors, mainly globotriaosylceramide (Gb3) or globotetraosylceramide (Gb4) which are found extensively on colonic, vascular epithelial, and kidney cells (Johannes and Römer 2010). Shiga toxins $1(\mathrm{Stx} 1)$ and $2(\mathrm{Stx} 2)$ are proteins encoded by chromosomally located phage-encoded genes (Page and Liles 2013). Intestinal epithelial cells are sensitive to Stx, which can cause damage by inhibiting the cellular protein synthesis, leading to bloody diarrhea, hemorrhagic colitis and hemolytic uremic syndrome (HUS). In the same way, kidney cells 
are also highly susceptible to Stx damage due to presence of $\mathrm{Gb} 3$ on this plasma membrane. When Stx reaches the kidneys via the bloodstream it might become a cause of localized thrombotic microangiopathy, it may progress to HUS (Vanaja et al. 2013). Children and the elderly are the most susceptible groups to EHEC-induced HUS (Mayer et al. 2012).

Additional virulence factors include EHEC hemolysin, catalase peroxidase, serine protease, type 1 fimbriae, p fimbriae and $\alpha$-hemolysin (Nguyen and Sperandio 2012). These factors contribute to the pathogenesis ranging from subverting host defenses to hijacking the host cell signaling which ultimately enables the bacteria to colonize, multiply, and cause disease.

\subsection{Host factors and modulation of virulence}

The human gastrointestinal tract is not a favorable environment for external invaders. Some of these bactericidal environments include gastric secretions and hydrochloric acid in the stomach, bile in the small intestine and antimicrobial peptides along the entire intestine.

The gastric acidic environment which can reach a $\mathrm{pH} 2.0$ because of the presence of hydrochloric acid, destroys a majority of pathogenic microorganisms that transit though the stomach (Gorden and Small 1993). However, EHEC O157:H7 is unusually resistant to acid and bile salt (Gunn 2000). The duodenum and jejunum are the sites where a very high concentration of bile exists which serves as another checkpoint for potentially pathogenic microorganisms. Bile is produced in the liver and stored in the gallbladder. In addition to 
aiding the digestion of fatty foods, bile has bactericidal properties (Begley et al. 2005). Human bile is a mixture of variety of components, such as proteins, ions, pigments, lipids and various bile salts (Begley et al. 2005). Cholate, deoxycholate, taurocholate, glycocholate, chenodeoxycholate, lithocholate are the main bile salts present in the bile. The intestinal microbial flora deconjugates the tauryl and glycyl group from cholate and chenodeoxycholate. The deconjugated primary bile salts can further be metabolized by the microbial flora to deoxycholate and lithocholate, respectively as shown in Fig 1 (Sorg and Sonenshein 2008). Bile salts are bactericidal by virtue of their DNA damaging and membrane disrupting properties. EHEC has the ability to resist bile salts and easily survive in the intestine (Prouty et al. 2004). This unique characteristic is achieved through efflux pumps that expel bile from the bacterial cell as well as the modification of membrane structures that reduce bile permeability. The bile salt concentration generally varies from $0.2-2.0 \%$ in the small intestine (Begley et al. 2005). The concentration decreases as bile salts are passively reabsorbed along the small intestine. 


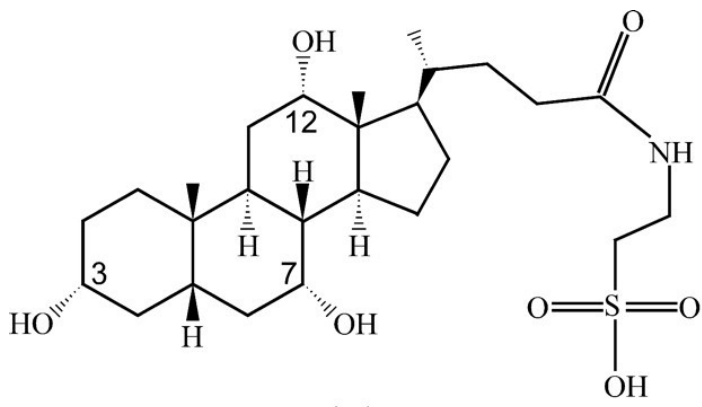

Taurocholate<smiles>C[C@H]1CC[C@H]2[C@@H]3[C@@H](O)C[C@H]4C[C@H](O)CC[C@]4(C)[C@H]3C[C@H](O)[C@]12C</smiles>

Cholate

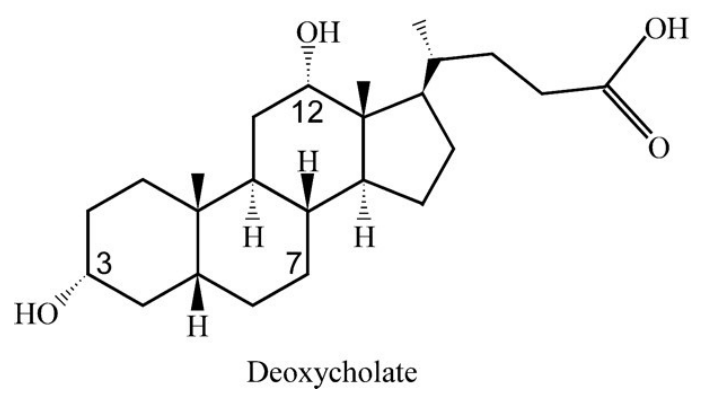

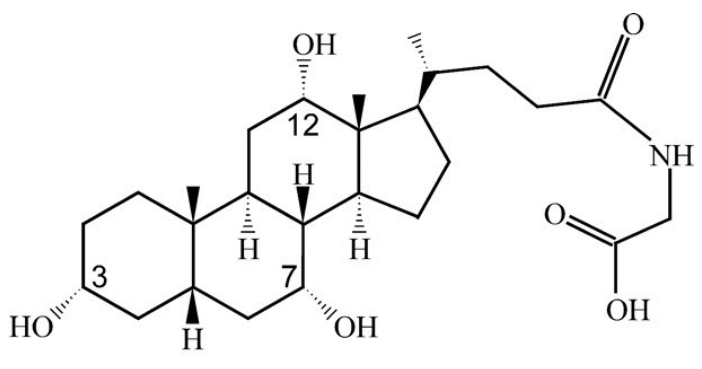

Glycocholate

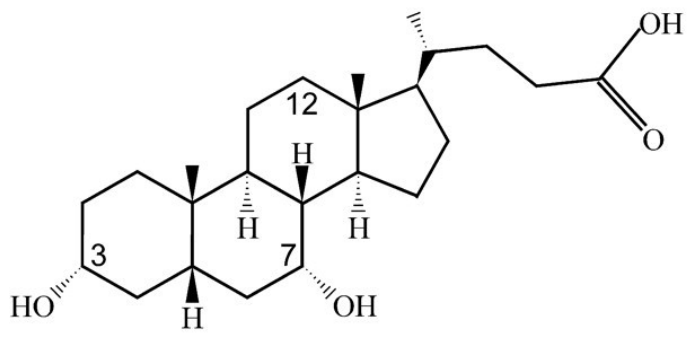

Chenodeoxycholate

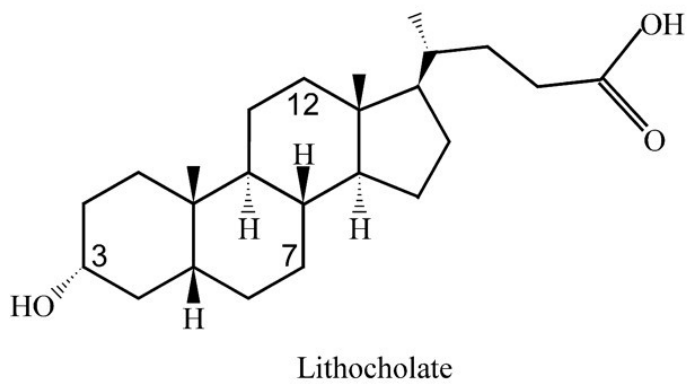

Figure 1 Structures of common primary and secondary bile acids: The primary bile salts cholate and chenodeoxycholate typically are conjugated with taurine or glycine. The secondary bile salts deoxycholate and lithocholate (Sorg and Sonenshein 2008).

Another major challenge to the pathogenic microorganism is the presence of a wide array of cationic antimicrobial peptides (CAMPs) on the epithelial surfaces of the entire gastrointestinal tract. CAMPs, mainly human alpha and beta-defensins and cathelicidins, 
are found as components of the innate immune system and serve as nonspecific defenses against microorganisms.

Responding to the environment is critically important for pathogens to colonize and establish infection within the host. They utilize environment-specific signals to directly regulate the expression of their unique virulence genes, thus giving them a competitive advantage over commensal flora. A successful pathogen like EHEC must overcome various gastrointestinal barriers encountered throughout the GI tract. EHEC has been shown to possess necessary mechanisms to deal with the above-mentioned challenges. Interestingly, EHEC not only survives these host challenges but also exploits them as the chemical signals to enhance expression of genes involved in survival and virulence. This is a subject of great curiosity for investigators working with enteric pathogens. In recent years there has been an explosion of interest in understanding the impact of gastrointestinal signals such as low acid, bile salts and short chain fatty acids in pathogenesis of these enteric bacteria. Exposure to low pH mimicking the stomach environment enhances host cell adhesiveness and motility in EHEC (House et al. 2009). In another study, Kus et al show that EHEC treatment with a physiologically relevant bile salt mixture promotes expression of many virulence associated genes including arn (pbgP) operon which assists EHEC to achieve increased resistance to cationic antimicrobial peptides (Kus et al. 2011). Analysis of bile salt mixture-induced EHEC gene expression revealed significant changes in the expression of numerous genes whose protein products are associated with modification of the Lipid A moiety of lipopolysaccharide. Modifications of lipopolysaccharides (LPS) in the cell envelope are recognized mechanisms that trigger resistance to cationic 
antimicrobial peptides (CAMP). CAMPs, acidic $\mathrm{pH}$, high ferric iron $\left(\mathrm{Fe}^{3+}\right)$, high aluminum $\left(\mathrm{Al}^{3+}\right)$ or low magnesium levels are the principal signals that stimulate the expression of lipid-modifying enzymes in gram-negative bacteria, resulting in increased CAMP resistance (Kim et al. 2006, Chen and Groisman 2013). These findings suggest that various sections of human gastrointestinal tract can serve as an important environmental cue for EHEC by triggering protective modifications of the bacterial outer membrane, thereby increasing resistance to human CAMPs.

Thus, EHEC has developed mechanisms to counteract many of the host innate defense mechanisms encountered along the entire gastrointestinal tract. When ingested by the human host, EHEC senses the changing environment inside the host though a number of two-component signaling systems. Instead of being killed in the intestine, EHEC undergoes an extensive remodeling of its outer membrane which enhance its resistance to host antimicrobial peptides.

\subsection{Cationic antimicrobial peptides}

Cationic antimicrobial peptides (CAMPs) are a structurally diverse group of molecules that are found virtually in all eukaryotes examined to date (Hancock and Diamond 2000). CAMPs are small molecular weight peptides usually made up of a few to hundred amino acids. They are ubiquitous in biological systems which are evolutionarily thought to be a component of the first line of defense against infectious agents. Because of the presence of 
high content of positively charged amino acids such as arginine, histidine and lysine, CAMPs are cationic molecules (Omardien et al. 2016). The cationic characteristic is an important feature of CAMPs, which initiates an electrostatic interaction of CAMPs with negatively charged phospholipid membrane of bacteria. These cationic peptides are involved in host defense through both direct bactericidal and immunomodulatory properties. They are critical components of the innate immune system by exhibiting broadspectrum activity against both gram-positive and gram-negative bacteria (Pazgier et al. 2013). Although thousands of CAMPs exist in nature, mammalian CAMPs can broadly be classified into three major classes: the $\alpha$ - and $\beta$-defensins and the cathelicidin as outlined in table 1.

Table 1 Major human cationic antimicrobial peptides: defensins and cathelicidins

$\begin{array}{llll}\begin{array}{l}\text { CAMP } \\ \text { family }\end{array} & \text { Subgroups } & \text { Tissue expression } & \text { Activity } \\ \begin{array}{l}\text { Defensins } \\ \alpha \text {-Defensins }\end{array} & \text { HNP-1-4 } & \begin{array}{l}\text { Phagocytic cells, bone } \\ \text { marrow, respiratory } \\ \text { tract }\end{array} & \begin{array}{l}\text { Antimicrobial and } \\ \text { immunomodulatory }\end{array} \\ & \text { HD-5 and HD-6 } & \begin{array}{l}\text { Paneth cell, HD-5 also } \\ \text { found in kidney and } \\ \text { reproductive tract }\end{array} & \begin{array}{l}\text { Antimicrobial and } \\ \text { immunomodulatory }\end{array} \\ \beta \text {-Defensins } & \text { HBD-1, HBD-2, } & \begin{array}{l}\text { GI tract, airway and } \\ \text { genitourinary } \\ \text { epithelium }\end{array} & \begin{array}{l}\text { Antimicrobial and } \\ \text { immunomodulatory }\end{array} \\ & \text { HBD-3, HBD-4 } & \begin{array}{l}\text { Small intestine, colon, } \\ \text { airway epithelium, bone } \\ \text { marrow }\end{array} & \begin{array}{l}\text { Antimicrobial and } \\ \text { immunomodulatory }\end{array} \\ \text { Cathelicidins } & \text { LL-37 } & & \end{array}$




\subsubsection{Defensins}

Defensins constitute one of the largest groups of CAMPs. Mammalian defensins contain six cysteine residues that form three characteristic disulphide bridges and can be divided into three classes ( $\alpha$-, $\beta$-and $\theta$-defensins). The three subfamilies mostly differ in their peptide length, structure of precursors and the sites of their expression (Schneider et al. 2005). Human $\alpha$-defensins are mainly expressed in neutrophils and the mucosal epithelial cells, including cells of gastrointestinal system where their primary function is to protect against microbial invasion (Sankaran-Walters et al. 2017). The $\alpha$-defensins, first identified in rabbit neutrophils and found exclusively in mammals. They are commonly known as classic defensins which contain 29-35 amino acids (Schneider et al. 2005) . $\beta$-defensins, as the name suggests, form $\beta$-sheets consisting of 30-50 amino acid residues. $\theta$-defensins are phylogenetically the youngest defensins which most probably appeared through mutation of a pre-existing $\alpha$-defensin gene. Active $\theta$-defensins are cyclic peptides found exclusively in non-human primates.

\subsubsection{Cathelicidins}

In humans, LL-37 is the most important cathelicidin which is produced by many cell types. The cathelicidins are a family of at least 30 structurally divergent antimicrobial peptides from various mammalian species (Fabisiak et al. 2016). As the name implies, they are characterized by having an evolutionarily conserved $\mathrm{N}$-terminal domain called the cathelin domain. The C-terminal domain, which is released by cleavage of proteases, has both 
antimicrobial and immunomodulatory properties (Doss et al. 2010). Cathelicidin peptides include protegrins from pigs, CAP-18 from rabbits, bactenecin and indolicidin from cows and more recently RL-37 from monkeys (Xhindoli et al. 2016). In humans, only one cathelicidin antimicrobial has been found to date, the $\alpha$-helical peptide LL-37 (also known as hCAP18, human cationic antimicrobial protein) (Xhindoli et al. 2016). Like defensins, cathelicidins are also stored as inactive propeptide precursors which, upon activation, are processed and released. Human cathelicidins are of major importance in enteric pathogen infection, particularly in EHEC infections (Yi et al. 2017).

As part of the defense system of the body, multiple classes of CAMPs are present throughout the various anatomical niches which are prone to attack by bacteria. The human HD5 and HD6, HBD1-6 and cathelicidin LL-37 establish a protective barrier against enteric pathogens and commensals in the GI tract (Le et al. 2017). Due to structural dissimilarity between prokaryotic and eukaryotic cells, most CAMPs preferentially target bacterial cells. Electrostatic interaction between the positively charged CAMPs with the negatively charged membrane surface of the microorganism is the main molecular mechanism underlying the binding (De Smet and Contreras 2005). After successful binding with the target organism, the CAMPs are reported to create pores within the microbial membrane which then cause leakage of ions, metabolites as illustrated in Figure 2 (Bevins and Salzman 2011). Successful enteric pathogens like EHEC have mechanisms to resist the antimicrobial action of CAMPS encountered in the gastrointestinal tract. 


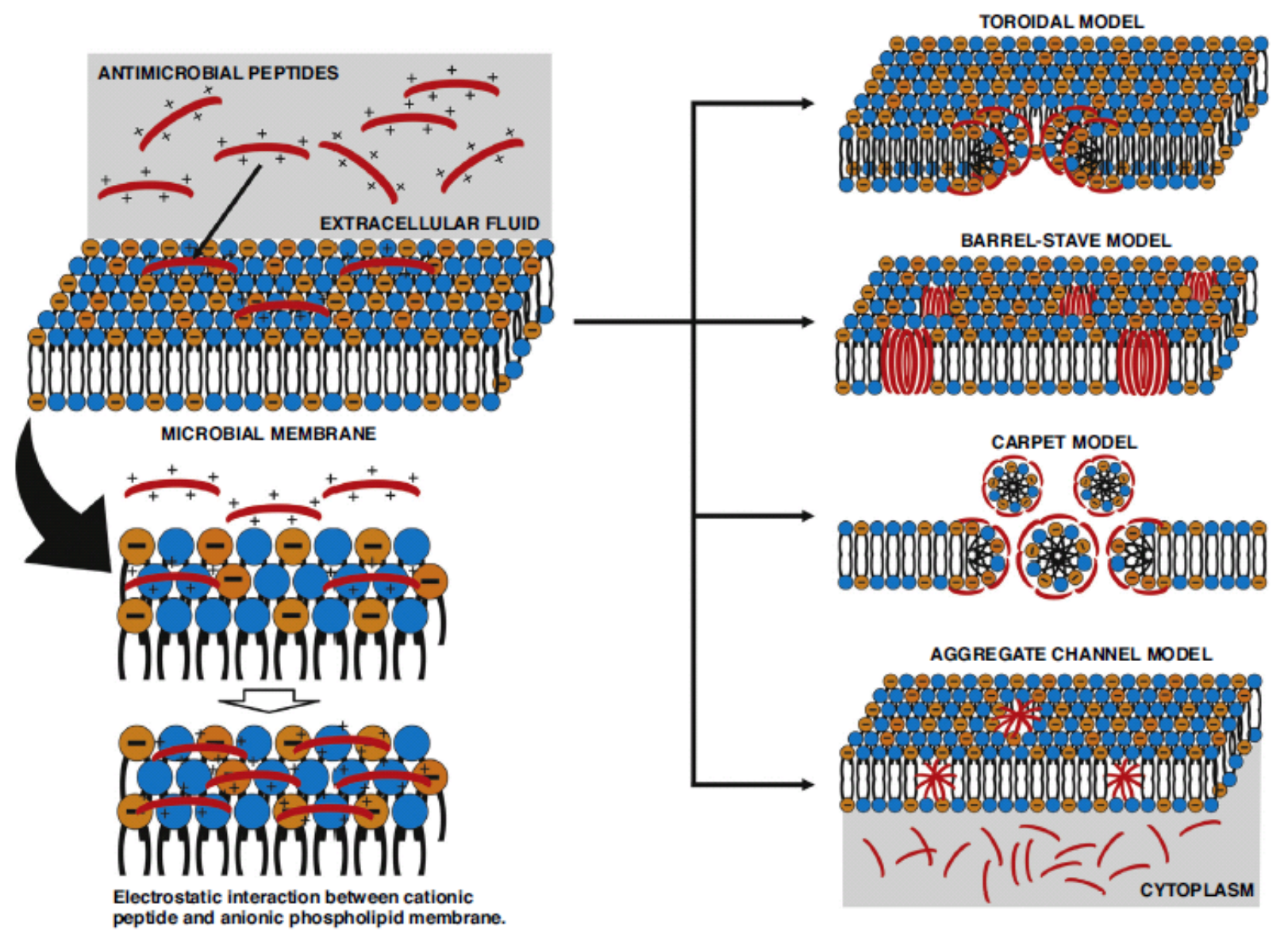

Figure 2 Proposed mechanisms of action of cationic antimicrobial peptides: Among the proposed mechanisms, the most cited are the toroidal model, barrel-stave model, and carpet model, all ultimately leading to pore formation and leakage of cellular content and cell death. (Sivieri et al. 2017) 


\subsection{Two-component regulatory systems and cross talk}

Enteric pathogens like EHEC encounter large variety of stressors mandating an urgent response inside and outside of the host whether it is food products or the human gastrointestinal tract. These can include stresses such as nutrient limitations, high acidity, presence of high iron and cationic antimicrobial peptides and bile salts. As a result, EHEC must manage to sense and appropriately respond to these stresses in order to survive. The two component regulatory system is a predominant signal transduction system present in prokaryotes and is responsible for sensing and responding to the external stimuli (Chen and Groisman 2013).

Typical two-component regulatory systems, as the name suggests, consist of two components, a transmembrane sensor (histidine) kinase that recognizes the external signal and a cytosolic response regulator that determines the response action of the organism in response to environmental changes (Jung et al. 2012). The sensor kinase gets activated by autophosphorylation when it encounters the appropriate signal. Activation of a sensor kinase leads to the transfer of the phosphoryl group to a conserved aspartate residue on its cognate response regulator (Jung et al. 2012). The response regulator is also a transcription factor whose DNA binding affinity for its promoters is modulated by phosphorylation which controls gene expression. PhoPQ and PmrAB systems are the major two-component systems involved in LPS modification in enterobacteriaceae. 


\subsubsection{PhoP/PhoQ}

The PhoPQ two-component system is composed of the sensor kinase PhoQ and its cognate response regulator PhoP. PhoQ's kinase activity is activated by low concentrations of $\mathrm{Mg}^{2+}$, acidic $\mathrm{pH}\left(\mathrm{H}^{+}\right.$ions) and the presence of cationic antimicrobial peptides but inactivated by high levels of $\mathrm{Mg}^{2+}$ ions (Omardien et al. 2016). In Salmonella, low $\mathrm{Mg}^{2+}$ concentration signals to the cell a transition from an extracellular environment to an intracellular location, increasing the phosphorylation of PhoP (PhoP-P) (Choi and Groisman 2017). This is a great advantage for survival to intracellular pathogens like Salmonella. Activation of PhoP-dependent genes leads to up-regulation of many virulence factors in enteric pathogens. Some of these include functions that remodel the bacterial outer membrane to help improve its barrier function.

\subsubsection{PmrA/PmrB}

Like PhoPQ, PmrAB is composed of the sensor kinase PmrB and its cognate regulator PmrA. The PmrAB two-component system is capable of sensing environmental cues such as acidic $\mathrm{pH}$, high $\mathrm{Fe}^{3+}$ ions, and the presence of CAMPs (Chen and Groisman 2013a). Exactly like PhoP-P, PmrA-P strongly bind to its target promoter and regulates gene expression that mediate lipid A modifications in bacterial outer membrane (Chen and Groisman 2013b). PmrAB is required for resistance to antimicrobial peptide PMB resistance in gram negative bacteria (Chen and Groisman 2013b). PmrAB-regulated LPS modifications can also reduce susceptibility to intestinal CAMPs present on the epithelial 
niches of intestine (Chen and Groisman 2013a). The products of PmrA-activated genes mediate the additions of compounds such as 4-aminoarabinose and phosphoethanolamine to lipid A which reduces the net negative charge of the gram negative outer membrane (Chen and Groisman 2013). The PmrAB is intimately connected with PhoPQ through a small protein, PmrD.

\subsubsection{PmrD}

The PMB Resistant Protein D (PmrD) is a connector protein thought to connect the bacterial two-component systems-PhoPQ to the PmrAB system. The PmrA/PmrB twocomponent system is the major regulator of gene products that modifies the LPS in a wide variety of pathogenic bacteria (Luo et al. 2013). In S. typhimurium and K. pneumoniae, activation of the PmrA/PmrB system occurs when the bacteria experience low $\mathrm{pH}$, or high $\mathrm{Fe}^{3+}$ environments, which are detected by the PmrB sensor kinase (Luo, et al 2013). In response to these inducing signals, PmrB autophosphorylates and then transfers the phosphoryl group to its response regulator PmrA. Phosphorylated PmrA is the active form of the protein that binds to the promoter region of DNA, promoting expression of variety of PmrA-dependent genes which are responsible for LPS modification (Zhou et al. 2001; Rubin et al. 2015). The expression of these PmrA-dependent genes mediates resistance to cationic antimicrobial peptides including PMB. 
Signals received by $\mathrm{PhoP} / \mathrm{PhoQ}$ and $\mathrm{PmrA} / \mathrm{PmrB}$ can be integrated to generate the appropriate cellular response in Salmonella (Kato and Groisman 2004). PmrD acts as a connector protein between these two signal transduction pathways. Early work suggested that the communication between these two pathways was not connected in E. coli (Winfield and Groisman, 2004). However, more recently, a study in E. coli, has demonstrated that the pmrA-dependent genes can also become activated indirectly through the cross-talk with PhoPQ under low magnesium environment via a small connector protein, PmrD, that stabilizes the activated state of the response regulator PmrA (Rubin et al. 2015) (Figure3).

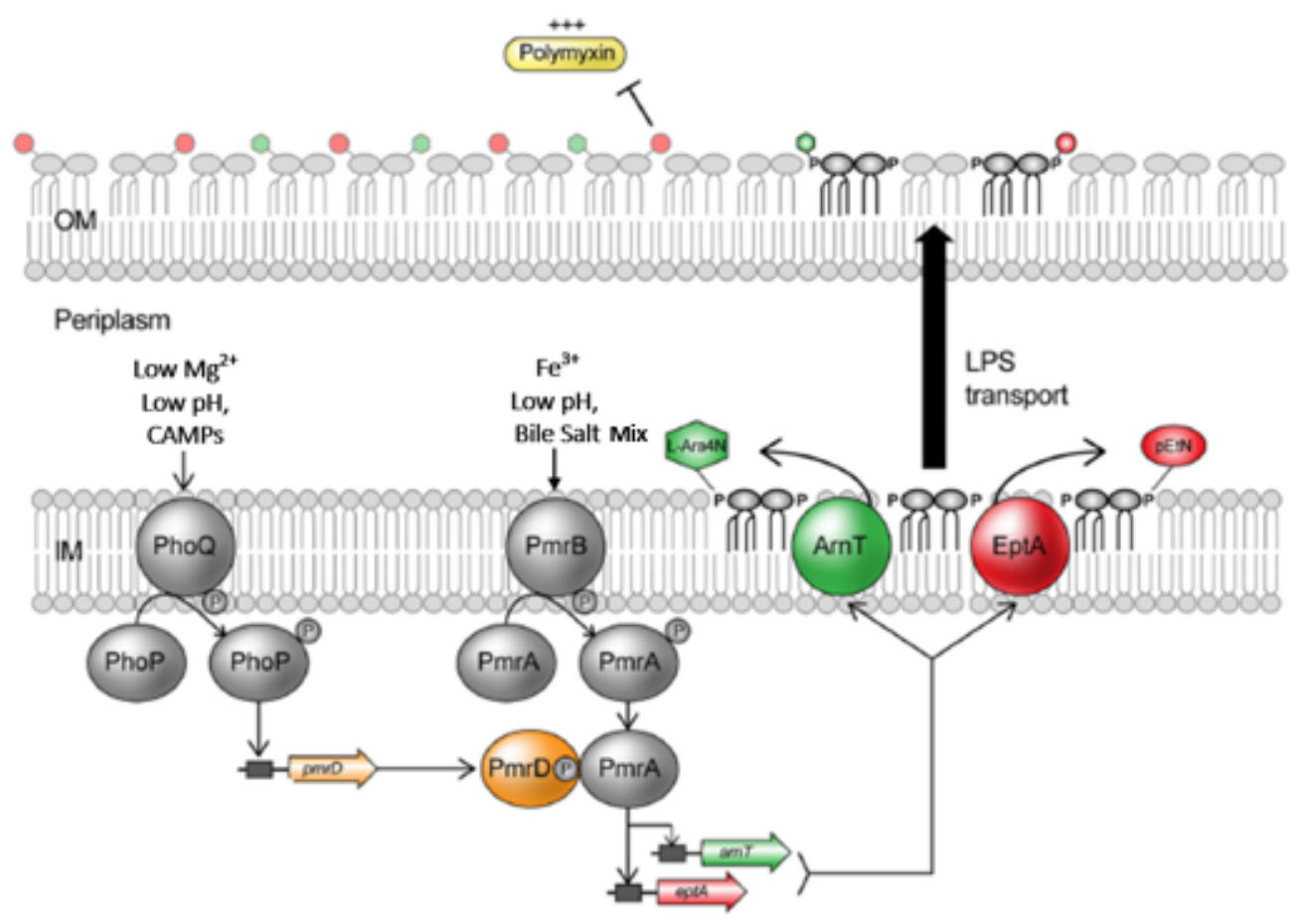

Figure 3 PhoP/PhoQ and PmrA/PmrB two-component systems in S. typhimurium and E. coli. $\mathrm{PhoP} / \mathrm{PhoQ}$ two component system gets activated when sensor kinase $\mathrm{PhoQ}$ is activated by signals like low $\mathrm{Mg}^{2+}$, CAMPs and low $\mathrm{pH}$ in the periplasm. PhoP, a response 
regulator of PhoP/PhoQ promotes transcription of the $p m r D$ gene. The PmrD protein binds to phospho-PmrA, a response regulator of PmrA/PmrB system. PmrD mechanically inhibits dephosphorylation of PmrA by PmrB, allowing continued transcription of PmrAdependent genes, including eptA and arnT. In the same way, sensor kinase PmrB when activated by signals like high $\mathrm{Fe}^{+3}$, low $\mathrm{pH}$ and bile salts, leads to phosphorylation of the response regulator, PmrA and promotes the same pathway (Rubin et al. 2015). Major lipid A modifying genes arnT and eptA, with their respective products are denoted by green and red. (adapted from Rubin et al., 2015)

A number of studies of gram-negative bacteria have indicated that lipid A modifications including addition of aminoarabinose and phosphoethanolamine which are associated with increased resistance to CAMPS are dependent on $\mathrm{pmrD}$ under low magnesium conditions (Kato, Latifi, \& Groisman, 2003, Luo et al., 2010, Rubin et al., 2015). However, interestingly, expression of $p m r D$ was only partially dependent on phoP under low magnesium conditions, suggesting that another as yet unidentified system was responsible for regulating expression of $p m r D$ under low magnesium conditions (Rubin et al. 2015). Under those conditions, $\mathrm{pmrD}$ expression was also not dependent on the presence of $\mathrm{pmrA}$ or $p m r B$. Nevertheless, under limiting magnesium conditions, expression of $p m r A$, the arn operon which governs amino-arabinose addition and eptA which is responsible for phosphoethanolamine modification were all dependent on the protein PmrD. However, resistance to PMB was dependent on $p m r D$ only under low magnesium conditions but not 
under mild acid inducing conditions. Therefore, although previous studies have indicated that mild acid induces CAMP resistance that is dependent on both PmrAB and PhoPQ, these recent findings suggest that the mild acid autonomously induces PmrAB and downstream activation of lipidA modifications, thereby bypassing $p m r D$. This would suggest that expression of $p m r A$, the arn operon and eptA would all be independent of pmrD under conditions such as mild acid that supposedly bypass $p m r D$. However, no evidence of this has been provided yet.

Physiological bile salt mixture and ferric iron are also known to induce CAMP resistance in a pmrAB dependent manner in EHEC (Kus et al. 2011). Based on the findings from the Rubin study, it is expected that bile salt or ferric iron induction should also bypass PmrD, thereby not requiring it for CAMP resistance nor affecting its expression. What is also not clear is how limiting magnesium or mild acid conditions would affect bile salt mixture or ferric iron-mediated effects. A recent study has indicated that mild acid induces significant EHEC resistance to PMB regardless of the presence of limiting magnesium (Francis A. 2017). This study also suggests that limiting magnesium enhances the induction of resistance by each of bile salt mixture and ferric iron, suggesting that PhoPQ plays at least a partial role in the induction of resistance by ferric iron and bile salts. Finally, interestingly, it appears that bile salt mixtures and ferric iron both stimulate PmrB-mediated changes through the same iron binding site on PmrB and so it is possible that the bile mixture may be enhancing the solubility or delivery of iron to PmrB (Francis A. Thesis 2017). 
Taken together, these data reveal a sophisticated, sensitive bacterial defense system for responding to stressful environmental conditions in the intestinal lumen, one that creates a more fortified, CAMP resistant membrane. Understanding how these various signals mediate CAMP resistance in EHEC and the specific roles of PmrD, PmrAB and PhoPQ in this resistance will provide valuable insight into how these host environmental signals affect EHEC fitness and virulence. 


\section{Thesis rationale}

EHEC is an important food and water borne pathogen. It continues to be a main cause of foodborne outbreaks as evidenced by frequent news and scientific articles, improved intervention in food industry or the treatment methods are essential. Due to the fact that EHEC's ability to survive in hostile environments such as gastrointestinal tract inside the host and outside the host in environments such as soil, food products and water, it poses a huge threat to human health and food industry (Avery et al. 2008). Lipopolysaccharide modification and subsequent host defense peptide resistance is the central mechanism by which enteric pathogens survives in GI tract and establish disease. This mechanism have been reported on many gram-negative pathogens of the enterobacteriaceae family that has the orthologs of the PmrA/PmrB two-component system, including $Y$. pestis (Lee et al. 2004), K. pneumoniae (Mitrophanov et al. 2008), and E. coli (Winfield and Groisman 2004). However, the two-component regulatory system that is being used to sense the local environment and enhance the resistance to CAMP, display considerable differences among the related species.

EHEC experiences various environments in the anatomical niches of GI tract during infection. The major microenvironments include low $\mathrm{pH}$, high iron and bile salt mixture. Earlier work in the Foster lab provided the evidence that physiological mix of bile salt enhances EHEC resistance to CAMPs (Kus et al. 2011). We hypothesize that EHEC may use these microenvironments as the signals to enhance CAMP resistance and that PhoPQ, 
PmrAB and PmrD all play varying roles in this resistance. The role of $p m r D$ in EHEC resistance to CAMPs is still poorly understood and more specifically with respect to $\mathrm{pH}$, bile salt mixture and ferric iron-induced conditions. This research project focuses on how these gastrointestinal cues are sensed and what strategies EHEC pursues to survive in the human host. The hypothesis and specific research objectives of this thesis are listed below. 


\section{Hypotheses and objectives}

\subsection{Central Hypothesis}

PmrD is critical for enterohemorrhagic Escherichia coli (EHEC) resistance to cationic antimicrobial peptides (CAMPs) induced by limiting magnesium but is irrelevant in each of bile salt mixture and ferric iron-induced resistance to CAMPS.

\subsection{Hypothesis 1}

In EHEC, PmrD plays a key role in low magnesium-induced resistance to PMB, but only a minor role in mild acid-induced resistance to PMB.

\subsubsection{Objective 1}

Determine the PMB resistance of WT EHEC and the isogenic pmrD mutant under varying combinations of low $(10 \mathrm{uM}) /$ high $(10 \mathrm{mM})$ magnesium and low (5.8)/neutral (7.0) $\mathrm{pH}$.

\subsection{Hypothesis 2}

In EHEC, PmrD plays no role in each of bile salt mixture and ferric-iron induced resistance to PMB. 


\subsubsection{Objective 2.1}

Determine the PMB resistance of WT EHEC and its isogenic $p m r D$ mutant under each of bile salt mixture-inducing and ferric iron-inducing conditions.

\subsubsection{Objective 2.2}

Assess the role of low magnesium in the induction of PMB resistance by each of bile salt mixture and ferric iron-induced resistance in both the WT and the isogenic pmrD mutant.

\subsection{Hypothesis 3}

In EHEC, $p m r D$ expression is sensitive to low magnesium but is insensitive to bile salt mixture or ferric iron or mild acid stimulation. Expression is partially dependent on phoP but is independent of $p m r A$ and $p m r B$.

\subsubsection{Objective 3.1}

Construct a translational GFP-pmrD reporter translational fusion in EHEC

\subsubsection{Objective 3.2}

Assess GFP levels in the GFP-pmrD reporter translational fusion in each of the strains after treatment with each of bile salt mixture, ferric iron and mild acid. Examine the effect of introducing low magnesium into the treatments. 


\section{Materials and methods}

\subsection{Bacterial strains, growth conditions and reagents}

Lysogeny broth (LB) with glycerol was used to store all strains at $-80^{\circ} \mathrm{C}$. Primary cultures of all strains were grown from glycerol stock on LB agar medium. Bacterial strains and plasmids used in this study can be found in Table 2. EHEC O156:H7 strain 86-24 was the wild type strain used in this study and all subsequent strains and mutants were derived from this strain.

Bacterial strains were grown in either LB broth ( $1 \%$ tryptone, $0.5 \%$ yeast extract and 0.5 $\% \mathrm{NaCl}$ ) or modified $\mathrm{N}$-minimal media (NM) supplemented with $0.1 \%$ casamino acids, 38 $\mathrm{mM}$ glycerol, $10 \mu \mathrm{M}$ or $10 \mathrm{mM} \mathrm{MgCl}_{2}$ and $100 \mu \mathrm{M} \mathrm{FeSO}_{4}$ as indicated in the experiment. $\mathrm{N}$-minimal media base contains $5 \mathrm{mM} \mathrm{KCI}, 7.5 \mathrm{mM}\left(\mathrm{NH}^{4}\right) \mathrm{SO}_{4}, 0.5 \mathrm{mM} \mathrm{K}_{2} \mathrm{SO}_{4}, 1 \mathrm{mM}$ $\mathrm{KH}_{2} \mathrm{PO}_{4}$. The $\mathrm{pH}$ of the medium was buffered with either $100 \mathrm{mM}$ Bis-Tris buffer $\mathrm{pH} 7.0$ or $\mathrm{pH}$ 5.8. When appropriate, LB broth or agar was supplemented with the appropriate antibiotic (Sigma) at the following concentrations: ampicillin $100 \mu \mathrm{g} / \mathrm{mL}$, kanarnycin 50 $\mu \mathrm{g} / \mathrm{mL}$, gentamicin $30 \mu \mathrm{g} / \mathrm{mL}$. N-minimal medium was used in all polymyxin B resistance and $p m r D$ promoter activity assays with appropriate high/low $\mathrm{Mg}^{+2}$ and $\mathrm{pH}$ conditions. $\mathrm{N}-$

minimal was supplemented with $1.5 \%$ bile salt mixture (Sigma-B-3426) and $100 \mu \mathrm{M}$ $\mathrm{FeSO}_{4}(\mathrm{BDH})$ wherever indicated in the experiment. 
A physiological bile salt mixture was purchased from Sigma (Burlington ON). The "Bile Salts Mixture" with Catalog Number B3426 was prepared from fresh bile, which was repeatedly extracted to purify and retain its inhibitory properties according to the manufacturer's data sheet.

Table 2 Bacterial strains used in the study

\begin{tabular}{|c|c|c|}
\hline \multicolumn{3}{|l|}{ Bacterial Strains } \\
\hline Strain & Description & Reference/ Source \\
\hline EHEC 86-24 & $\begin{array}{l}\text { Clinical isolate of } \mathrm{O} 157: \mathrm{H} 7 \text { serotype of } \\
\text { enterohemorrhagic Escherichia coli }\end{array}$ & $\begin{array}{l}\text { Dr. Jorge Giron, } \\
\text { University of } \\
\text { Florida }\end{array}$ \\
\hline S17-1 $\lambda$ pir : pRE112 & $\begin{array}{l}\text { S17-1 } \lambda \text { pir (conjugative donor strain for } \\
E \text { coli) with pRE112-GmR with } \Delta p m r D \\
\text { deletion construct }\end{array}$ & McPhee Lab \\
\hline EHEC 86-24 & pmrD deletion mutant & This study \\
\hline S17-1 $\lambda$ pir : pRE112 & $\begin{array}{l}\text { S17-1 } \lambda \text { pir (conjugative donor strain for } \\
E \text { coli) with pRE112-GmR with } \triangle p h o P \\
\text { deletion construct }\end{array}$ & McPhee Lab \\
\hline EHEC 86-24هphoP & phoP deletion mutant & This study \\
\hline
\end{tabular}




\begin{tabular}{|c|c|c|}
\hline $\begin{array}{l}\text { EHEC 86-24 } \\
\text { ApmrD:pBADGr:: } \\
\text { pmrD }\end{array}$ & $\begin{array}{l}\text { 86-24 transformed with vector } \mathrm{pBADGr} \\
\text { containing full } \mathrm{pmrD} \text { coding sequence }\end{array}$ & This study \\
\hline 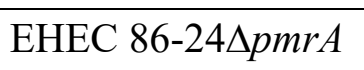 & pmrA deletion mutant & Kus et al., 2011 \\
\hline EHEC 86-24 $\Delta p m r B$ & $p m r B$ deletion mutant & Kus et al., 2011 \\
\hline \multicolumn{3}{|l|}{ Plasmids } \\
\hline pKD4 & FRT-flanked; KanR & $\begin{array}{l}\text { (Datsenko and } \\
\text { Wanner 2000) }\end{array}$ \\
\hline pKD46 & Lambda-Red helper plasmid; AmpR & $\begin{array}{l}\text { (Datsenko and } \\
\text { Wanner 2000) }\end{array}$ \\
\hline pRE112 & $\begin{array}{l}\text { Suicide vector for allelic exchange with } \\
\text { Sac } B \text { gene }\end{array}$ & McPhee Lab \\
\hline pBADGr & $\begin{array}{l}\text { expression vector with L-arabinose } \\
\text { inducible promoter }\end{array}$ & Kus et al., 2011 \\
\hline pCR2.1 TOPO & $\begin{array}{l}\text { Commercially available TA Cloning } \\
\text { vector, Invitrogen }\end{array}$ & $\begin{array}{l}\text { Catalog \# } \\
\text { K450002 }\end{array}$ \\
\hline
\end{tabular}




\subsection{Bacterial strain construction}

\subsubsection{Construction of pmrD and phoP isogenic mutants}

Each of $p m r D$ and $p h o P$ targeting allelic exchange construct cloned in pRE112-Gm (GmR) vector were generously provided by McPhee lab in $E$. coli $\mathrm{S} 17-1 \lambda$ pir strain. pRE112 is a suicide plasmid which can only replicate in bacterial strains containing lambda pir (conjugative strain able to host lambda pir-dependent plasmids). The recipient (EHEC 8624 [pKD46]) was then prepared. The donor pRE112 (GmR) containing the target construct and the recipient were allowed to mate, selected, the selective markers were removed. Selected colonies were screened by colony PCR. The isogenic $p m r D$ and $p h o P$ mutant were verified using PCR and DNA sequencing results (The Centre for Applied Genomics, Hospital for Sick Children, Toronto, Ontario, Canada). When grown in LB, the growth characteristics of $p m r D$ and phoP mutant were not very different than that of WT EHEC 86-24.

\subsubsection{Construction of $\triangle p m r D$ complementation strain}

A complemented $\triangle p m r D$ strain was constructed by using pBADGr expression vector. pmrD coding sequences were placed under the L-arabinose inducible $\mathrm{pBAD}$ promoter. The coding sequence of $p m r D$ was amplified from WT 86-24 using specially designed primers, Comp1 and Comp2 from Table 3. Restriction digestion of this PCR product and pBADGr vector were carried out with $X b a I$ and HindIII. This PCR product and $p B A D$ digested with the same restriction enzymes were ligated using DNA ligase and transformed into 
chemically competent $p m r D$ mutant strain. As the final step, the sequence was verified by DNA sequencing, using $\mathrm{pBAD}$ sequencing primer Seq $\mathrm{F}$ and Seq $\mathrm{R}$ as mentioned in Table 3.

\subsubsection{Construction of reporter plasmid}

The 500bp region upstream of $p m r D$ (this region contains the promoter sequence of $p m r D$ ) and the 500bp region downstream of $p m r D$ regions were amplified from WT EHEC (EHEC 86-24) with the oligonucleotides P1/ P2 and P5/P6 in a BIO-RAD C1000-Touch thermal Cycler. Similarly, the $g f p_{m u t 3}$ coding sequences were amplified from GFP plasmid (p3174) with oligonucleotides $\mathrm{P} 3 / \mathrm{P} 4$ where $\mathrm{P} 3$ and $\mathrm{P} 4$ are chimeric oligonucleotides that possess the complementary sequences of upstream and downstream regions of $p m r D$ as well as the sequences that are designed to amplify the coding sequences of $g f p$ from $\mathrm{p} 3174$. The sequences of the oligonucleotides used in this work are described in Table 3.0. All the three PCR reactions were carried out with high fidelity DNA polymerase (Phusion HF polymerase). Once all three fragments were amplified, they were verified on agarose gel for their appropriate sizes. Then all the three fragments were stitched together by SOE PCR and the resulting $1700 \mathrm{bp}$ fragment was confirmed by agarose gel. The $p m r D$-gfp-pmrD linear construct was then cloned into pCR2.1 TOPO vector (Invitrogen) as per the kit guideline. The cloned fragment was confirmed by DNA sequencing result. The $p m r D-g f p$ reporter plasmid was miniprepped and transformed into $p m r D$ mutant strain to generate the $\operatorname{pmrD-gfp}$ reporter strain. 
In order to measure the background auto-fluorescence, a control strain lacking the gfp fluorescence reporter was also constructed. The control strains (harboring TOPO plasmid but not $p m r D$-gfp construct) were prepared by transforming the empty TOPO into $p m r D$ mutant strain.

Table 3 List of oligonucleotides used in the study

\begin{tabular}{|l|l|c|}
\hline Name & \multicolumn{1}{|c|}{ Sequence } & Source \\
\hline P1 & GTTTCACTGGTTAATGACGAAGGCTGGTACG & This study \\
\hline P2 & $\begin{array}{l}\text { GAAAAGTTCTTCTCCTTTACGCATTGTATTATCCTGTT } \\
\text { TGCTAAGAGTTTTC }\end{array}$ & This study \\
\hline P3 & $\begin{array}{l}\text { GAAAACTCTTAGCAAACAGGATAATACAATGCGTAAA } \\
\text { GGAGAAGAACTTTTC }\end{array}$ & This study \\
\hline P4 & $\begin{array}{l}\text { CCTGCCCACGACAAAACAACGTTATTTGTATAGTTCAT } \\
\text { CCATGCCATG }\end{array}$ & This study \\
\hline P5 & $\begin{array}{l}\text { CATGGCATGGATGAACTATACAAATAACGTTGTTTTG } \\
\text { TCGTGGGCAGG }\end{array}$ & This study \\
\hline P6 & GAATTTTGTCTGGGTGACGCTGGCTGCAG & This study \\
\hline Comp & $\begin{array}{l}\text { GCGCGCTCTAGAGAATGGCTGGTCAAAAAA } \\
\text { F }\end{array}$ & This study \\
R
\end{tabular}

Underlined sequences are the targets of restriction enzymes used in the primers 


\subsection{Polymyxin B (PMB) resistance assay}

Bacterial cells were grown overnight at $37^{\circ} \mathrm{C}$ in $\mathrm{N}$-minimal medium with or without treatment with BSM (bile salt Sigma-B-3426) or/ $\mathrm{Fe}^{3+}\left(\mathrm{BDH} \mathrm{FeSO}_{4}\right)$ as stated in the individual experiment under varying conditions of high/low $\mathrm{pH}$ and $/ \mathrm{or}^{\mathrm{M}} \mathrm{g}^{+2}$. The next day, cultures were diluted 1:100 in respective medium again and incubated for 3 to 6 hours at $37^{\circ} \mathrm{C}$ with shaking until they reach mid-log phase $\left(\mathrm{OD}_{600} 0.4-0.6\right)$. Cells were spun down, washed with PBS $(\mathrm{pH}$ 7.2) three times to remove the pretreatment agent and resuspended in $\mathrm{N}$-minimal salts buffered at $\mathrm{pH} 7.0 . \mathrm{OD}_{600}$ was again recorded. The live cell density was then adjusted to $1 \times 10^{8} \mathrm{CFU} / \mathrm{mL}$ with $\mathrm{N}$-minimal salts buffered at $\mathrm{pH} 7.0$ for both pretreatment group and untreated groups. A 1/100 dilution $\left(1 \times 10^{6} \mathrm{CFU} / \mathrm{mL}\right)$ was then subjected to killing by freshly prepared cationic antimicrobial peptide polymyxin B (PMB). $100 \mu \mathrm{L}$ of each preparation were mixed with $100 \mu \mathrm{L}$ of appropriate concentration of polymyxin B (Sigma) and the other $100 \mu \mathrm{L}$ mixed with PBS. All killing assays were incubated at $37^{\circ} \mathrm{C}$ for $1 \mathrm{~h}$ under static condition. Serial dilutions of each culture were prepared in PBS and plated on LB agar plates for CFU enumeration. Survival values were calculated by dividing the number of CFU following treatment with PMB relative to those incubated in the presence of PBS and then multiplied by 100 (protocol details provided in the Appendix). For each result, three independent experiments were performed with three technical replicates. 


\subsection{GFP reporter assays}

Overnight cultures of $p m r D$ reporter strains (carrying $g f p$ under $p m r D$ promoter in the TOPO plasmid) and pmrD control strain (carrying only TOPO plasmid) were centrifuged, washed, and resuspended in respective medium (low/high $\mathrm{Mg}^{+2}$ with or without BSM or $\mathrm{Fe}^{3+}$ ) and adjusted to $0.1 \mathrm{OD}_{600} .200 \mu \mathrm{l}$ of each cell suspension was immediately transferred into a 96-well plate and the cultures were grown in a Synergy HTX fluorescent plate reader (Biotek) at $37^{\circ} \mathrm{C}$ under continuous shaking mode. The cell density $\left(\mathrm{OD}_{600 \mathrm{~nm}}\right)$ and fluorescence (using a 485/20 nm excitation filter and a 528/20 nm emission filter) were monitored every $15 \mathrm{~min}$ for $16 \mathrm{~h}$. The GFP fluorescence and the corresponding $\mathrm{OD}_{600}$ readings were retrieved from the machine and divided to generate the normalized ratio value of relative fluorescence units $(\mathrm{RFU}) / \mathrm{OD}_{600}$. Values were then adjusted for background by subtracting the normalized ratio value obtained for the corresponding control strain (protocol details provided in the Appendix). The fluorescence was calculated as relative fluorescent units (RFU) per OD600 of each well by using the following formula.

$$
\left(\frac{G F P_{\text {reporter }}-\mathrm{GFP}_{\text {medium }}}{\mathrm{OD}_{\text {reporter }}-\mathrm{OD}_{\text {medium }}}\right)-\left(\frac{\mathrm{GFP}_{\text {control }}-\mathrm{GFP}_{\text {medium }}}{\mathrm{OD}_{\text {control }}-\mathrm{OD}_{\text {medium }}}\right)
$$

\subsection{Synergy assays}

Synergy between BSM and PMB was tested using the checkerboard method as described by CLSI (Clinical Laboratory Standard Institute, 2007). The total fractional inhibitory concentration (FIC) for interactions between BSM and PMB was determined. Double 
dilutions of appropriate concentrations of the BSM and PMB were prepared in respective medium low $\mathrm{Mg}^{+2}$-neutral $\mathrm{pH}$ and high $\mathrm{Mg}^{+2}$-neutral $\mathrm{pH} .50 \mu 1$ of double dilutions of $\mathrm{BSM}$ and PMB and the $50 \mu 1$ of $2 \times 10^{5} \mathrm{CFU} / \mathrm{mL}$ log-phase bacterial suspension prepared in low $\mathrm{Mg}^{+2}$-neutral $\mathrm{pH}$ and high $\mathrm{Mg}^{+2}$-neutral $\mathrm{pH}$ medium were mixed and incubated for 18 hours at $37^{\circ} \mathrm{C}$ under static conditions. Plate readings were done with HTX Microplate Reader (Biotek) after 18 hours. The following calculation techniques were used to estimate the individual and the final FIC of BSM and PMB as described in conventional antimicrobial susceptibility testing methods (Jenkins and Schuetz 2012).

FIC of BSM $=\frac{\text { BSM MIC when tested in combination with PMB }}{\text { BSM MIC alone }}$

FIC of PMB $=\underline{\text { PMB MIC when tested in combination with BSM }}$

PMB MIC alone

Total FIC $=$ FIC of BSM + FIC of PMB

The total FIC values were interpreted as follows:

\begin{tabular}{|c|c|}
\hline Synergistic & $\leq 0.5$ \\
\hline Indifferent & $>1.0-4.0$ \\
\hline Antagonistic & $>4.0$ \\
\hline
\end{tabular}




\section{Statistical Analysis}

Results were presented as means \pm standard error of mean from at least three biological replicates. To test statistical significance among multiple groups, a one-way ANOVA with post-hoc comparisons with Tukey's method were used where appropriate, assuming standard level of significance $(<0.05)$. The data were analyzed using GraphPad Prism 5.0 software (GraphPad Software Inc. San Diego, CA). Level of significance was indicated on Figures using asterisk $(*)$ mark. 


\section{Results}

\subsection{Low $\mathrm{Mg}^{+2}$ and mild acid signal promotes PMB resistance in EHEC through specific two-component systems}

One hour killing assays were used to assess PMB resistance of each strain after pretreatment with selected media. Initial PMB resistance assays examined EHEC 86-24 WT and $p m r D$ mutant without any specific inducing signals in the medium. Figure 4A shows the results of the experiment carried out in N-minimal medium without any known PmrAB or PhoPQ activating signals. The survival rates of both $\mathrm{WT}$ and $\triangle p m r D$ strains decline significantly after exposure to $2 \mu \mathrm{g} / \mathrm{ml}$ PMB compared to untreated strains. Only $28 \%$ of WT and $18 \%$ of $p m r D$ survived the PMB treatment. There is no significant difference in survival of WT and $p m r D$ mutant after PMB challenge.

Figure 4B shows results for the same experiment as Figure 4A except that it was done under mild acidic condition (pH 5.8). Mildly low $\mathrm{pH}$ is a signal that is thought to be sensed by both two component systems as demonstrated in Salmonella typhimurium and Shigella flexneri (Prost et al., 2007, Lin et al., 2018) . However, it is still unclear how EHEC responds to mildly low $\mathrm{pH}$. The PMB survival rate of $\mathrm{WT}$ and $p m r D$ mutant strains grown at $\mathrm{pH} 5.8$ and high $\mathrm{Mg}^{+2}(10 \mathrm{mM} \mathrm{MgCl} 2)$ increased compared to strains grown at nonactivating (high $\mathrm{Mg}^{+2}$ and neutral $\mathrm{pH}$ ) condition. However, no significant difference

observed between WT and $p m r D$ mutant. Growth at $\mathrm{pH} 5.8$ did not significantly affect the PMB survival of $p m r D$ mutant relative to the WT. As no sign of $p m r D$ involvement appears 
here, these results suggest that PhoPQ signal transduction pathway is not the main low $\mathrm{pH}$ sensing strategy in EHEC 86-24. Further experiment with $\triangle p m r B$ shows that PMB resistance of $\triangle p m r B$ significantly decreases with low $\mathrm{pH}$ as shown in Figure 4D. This is an interesting finding showing how EHEC responds to the low $\mathrm{pH}$ condition as opposed to Salmonella typhimurium where PhoQ has also been shown to be activated by mildly low $\mathrm{pH}$ for survival adaptation. From the same experiment, it appears that low $\mathrm{pH}$ induced PMB resistance is also dependent on $p h o P$.

Figure 4C shows a significant difference in PMB survival between WT and $p m r D$ mutant grown in limiting $\mathrm{Mg}^{+2}$ and neutral $\mathrm{pH}$ conditions. Survival rate of PMB-treated $p m r D$ mutant significantly declines in low $\mathrm{Mg}^{+2}$ and neutral $\mathrm{pH}$ condition. This means $\mathrm{pmrD}$ inactivation significantly impairs PMB resistance when grown in $\mathrm{Mg}^{+2}$-limiting environment Moreover, complementation of $p m r D$ restores the PMB survival phenotype to WT levels. These results confirm that $\operatorname{pmrD}$ plays a key role in low $\mathrm{Mg}^{+2}$-induced resistance to PMB. 


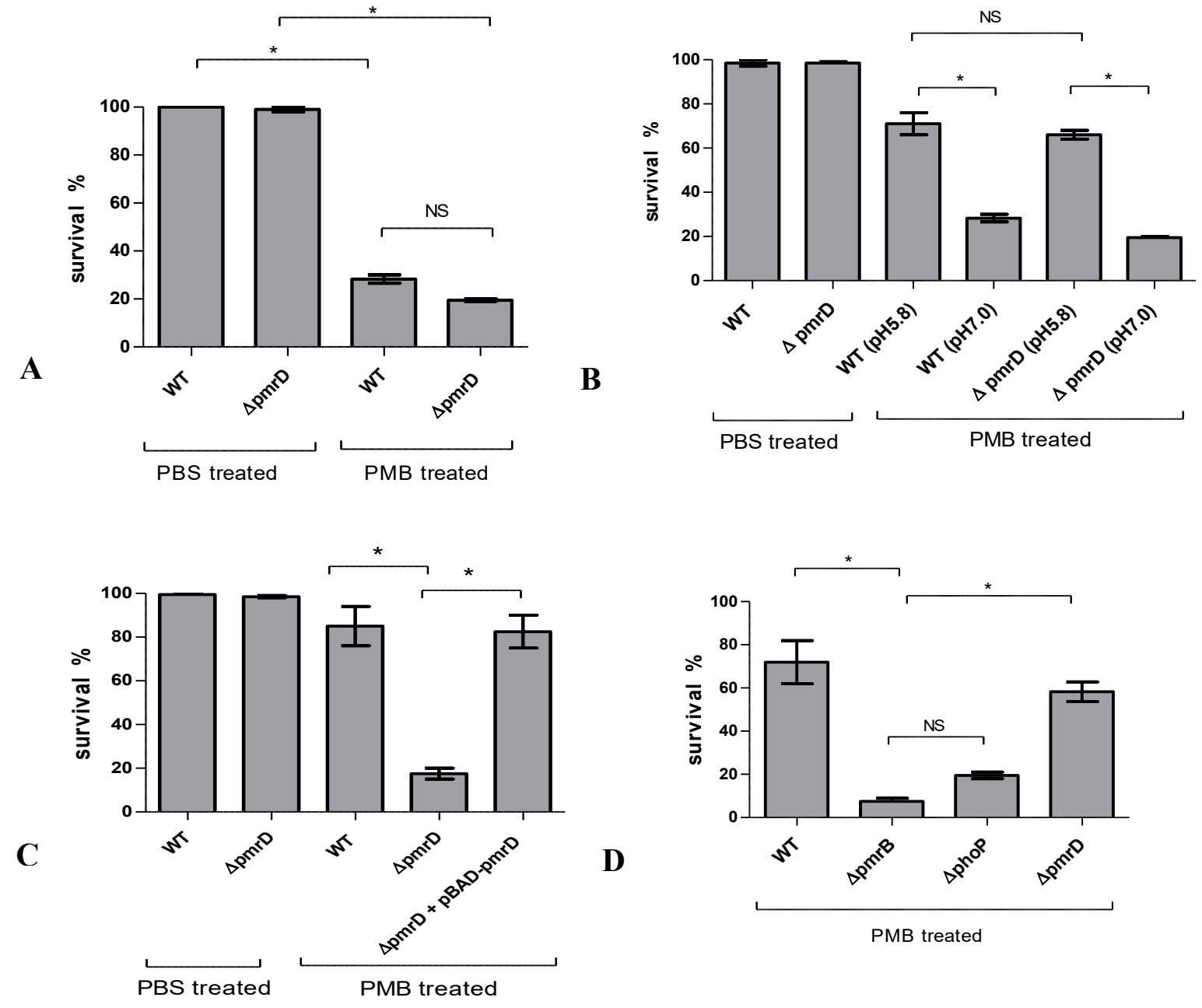

Figure 4 Low $\mathrm{Mg}^{+2}$ and mild acid both promote PMB resistance in EHEC 86-24 differently: A) PMB resistance minimal without activating signals in both WT EHEC and $\triangle p m r D$. B) Survival rate of EHEC 86-24 WT and $p m r D$ mutant after PMB treatment cultured in $\mathrm{N}$-minimal medium supplemented with high $\mathrm{Mg}^{+2}(10 \mathrm{mM} \mathrm{MgCl} 2)$ and buffered at low $\mathrm{pH}(5.8)$ and neutral $\mathrm{pH}$ 7.0 C) Survival rate of EHEC 86-24 WT and pmrD mutant after PMB treatment cultured under low $\mathrm{Mg}^{+2}\left(10 \mu \mathrm{M} \mathrm{MgCl}_{2}\right)$ and neutral $\mathrm{pH}$ (7.0). pBADGr induction carried out with $0.2 \%$ L-Arabinose. D) Survival rate of EHEC 86-24 WT, $p m r B$, phoP and pmrD mutant after PMB treatment cultured in N-minimal medium 
supplemented with high $\mathrm{Mg}^{+2}(10 \mathrm{mM} \mathrm{MgCl}$ ) and buffered at low $\mathrm{pH}$ (5.8). Data bars represent means \pm SEMs, $N=3$. One-way ANOVA followed by Tukey's post-hoc test. * $P<0.05$.

\subsection{Exposure to physiological relevant bile salt mixture induces PMB resistance in EHEC 86-24}

Figure 5A shows that survival rates significantly decline in both strains when exposed to PMB for 1 hour for indicated strains grown in high $\mathrm{Mg}^{+2}$ and neutral $\mathrm{pH}$ medium. However, pre-treatment with $1.5 \%$ BSM significantly increases the survival ability in both strains. pmrD inactivation did not affect this resistance phenotype. This suggests that $p m r D$ does not play an important role in bile salt mixture-induced PMB resistance in high $\mathrm{Mg}^{+2}$ and neutral $\mathrm{pH}$ condition.

Figure 5B shows that under low $\mathrm{Mg}^{+2}$ and neutral $\mathrm{pH}$ conditions WT strain has a significantly higher PMB survival rate than the $p m r D$ mutant. Introducing BSM (as a signal) did not change the PMB survival of WT or mutant. These PMB survival levels indicate that under low $\mathrm{Mg}^{+2}$ condition, BSM signal did not enhance survival possibly because the low $\mathrm{Mg}^{+2}$ induction swamps out the BSM induction of resistance. Secondly, the results indicate that $p m r D$ is required for PMB survival under low $\mathrm{Mg}^{+2}$ conditions and may be necessary for BSM induction of resistance under these conditions. 

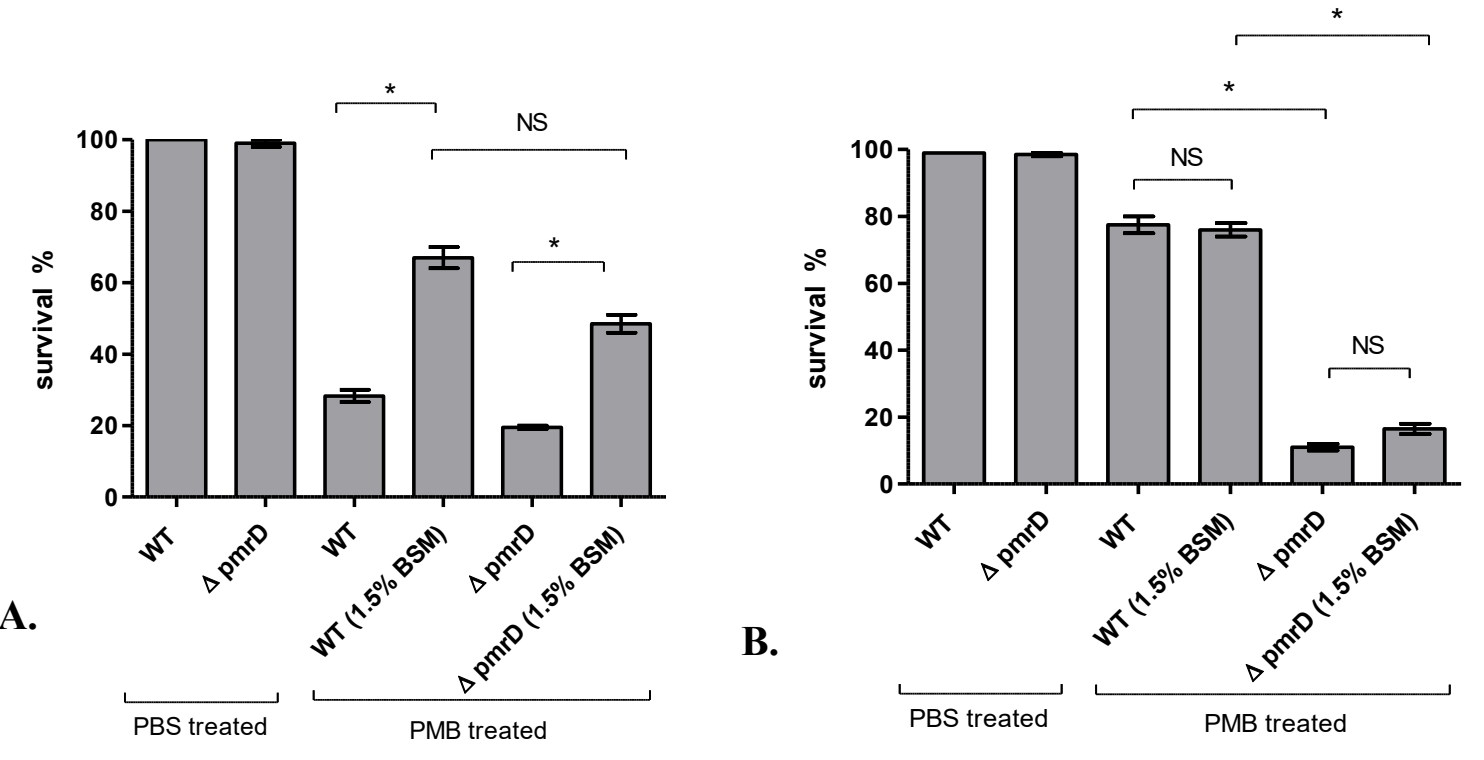

Figure 5 Bile salt mixture treatment increases the PMB resistance in WT and pmrD mutant under high $\mathrm{Mg}^{+2}$ at neutral $\mathrm{pH}$ but not under low $\mathrm{Mg}^{+2}$ at neutral $\mathrm{pH}$ : A) Survival rate of EHEC 86-24 WT and pmrD mutant after PMB treatment cultured under high $\mathrm{Mg}^{+2}\left(10 \mathrm{mM} \mathrm{MgCl}_{2}\right)$ and neutral $\mathrm{pH}(7.0)$ and with or without BSM as pre-treatment. B) Survival rate of EHEC 86-24 WT and $p m r D$ mutant after PMB treatment cultured under low $\mathrm{Mg}^{+2}(10 \mu \mathrm{M} \mathrm{MgCl})$ and neutral $\mathrm{pH}(7.0)$ and with or without BSM as pre-treatment. Data shown are the means \pm SEMs, $N=3$, One-way ANOVA followed by Tukey's post-hoc test. $* \mathrm{P}<0.05$.

\subsection{Exposure to high iron induces PMB resistance in EHEC 86-24}

High iron $\left(100 \mu \mathrm{M} \mathrm{FeSO}_{4}\right)$ treatment increases the PMB resistance in WT and $p m r D$ mutant 
in high $\mathrm{Mg}^{+2}$ at neutral $\mathrm{pH}$ as well as in low $\mathrm{Mg}^{+2}$ at neutral $\mathrm{pH}$. Figure $6 \mathrm{~A}$ shows results of the experiment conducted at high $\mathrm{Mg}^{+2}\left(10 \mathrm{mM} \mathrm{MgCl}_{2}\right)$ and neutral $\mathrm{pH}$ with $\mathrm{Fe}^{3+}$ $\left(100 \mu \mathrm{M} \mathrm{FeSO}_{4}\right)$ as pre-treatment. Survival rates significantly declines in both strains when exposed to PMB. However, pre-treatment with high iron significantly increases the PMB survival ability in both strains. $p m r D$ inactivation did not affect this resistance phenotype. It suggests $p m r D$ does not play important role in high iron-induced PMB resistance under high $\mathrm{Mg}^{+2}$ and neutral $\mathrm{pH}$ condition.

Figure 6B shows results for the same experiment performed under low $\mathrm{Mg}^{+2}$ at neutral $\mathrm{pH}$. Introducing $\mathrm{Fe}^{3+}$ as a signal into the low $\mathrm{Mg}^{+2}$ medium significantly increased the survival rate of $p m r D$ mutant whereas no significant change was observed in WT strain. These results indicate that EHEC does not require $\operatorname{pmrD}$ for sensing $\mathrm{Fe}^{3+}$ as an environmental signal even under low $\mathrm{Mg}^{+2}$ conditions.
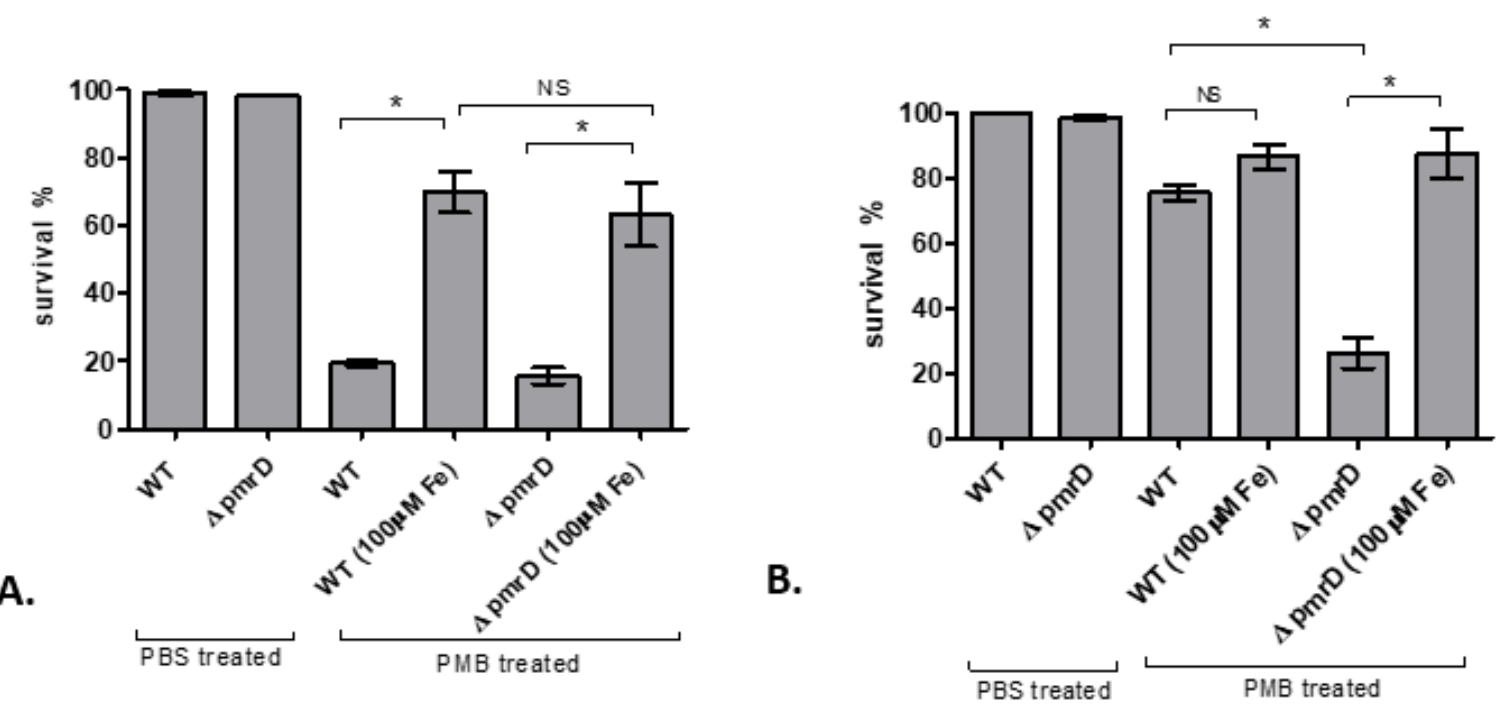
Figure 6 Iron-induced PMB resistance is independent of PmrD: A) Survival rate of EHEC 86-24 WT and pmrD mutant after PMB treatment cultured under high $\mathrm{Mg}^{+2}(10$ $\mathrm{mM} \mathrm{MgCl}_{2}$ ) and neutral $\mathrm{pH}$ (7.0) and with or without $\mathrm{Fe}^{3+}$ as pre-treatment. B) Survival rate of EHEC 86-24 WT and pmrD mutant after PMB treatment cultured under low $\mathrm{Mg}^{+2}$ $\left(10 \mu \mathrm{M} \mathrm{MgCl}_{2}\right)$ and neutral $\mathrm{pH}(7.0)$ and with or without $\mathrm{Fe}^{3+}$ as pre-treatment. Data shown are the means \pm SEMs, $\mathrm{N}=3$, One-way ANOVA followed by Tukey's post-hoc test. $* \mathrm{P}<$ 0.05 .

\subsection{BSM and $\mathrm{Fe}^{3+}$-induced PMB resistance is dose-dependent}

Previous experiments have shown that the two signals - BSM and $\mathrm{Fe}^{3+}$ have the ability to induce CAMP resistance in EHEC. PmrA/PmrB signal transduction pathway is thought to be involved in sensing these signals in EHEC. To determine whether these signals could have additive effects, we repeated the experiment by growing WT and pmrD mutant in 10 $\mathrm{mM} \mathrm{MgCl}_{2}$ with low concentrations of $\mathrm{BSM}$ or $\mathrm{Fe}^{3+}$ first and then increasing the concentration of each signal- $\mathrm{BSM}$ and $\mathrm{Fe}^{3+}$ separately as indicated in the Figure $7 \mathrm{~A}$ and B. With increasing concentration of either $\mathrm{BSM}$ or $\mathrm{Fe}^{3+}$, the rate of PMB survival increases in both WT and pmrD mutant under high $\mathrm{Mg}^{+2}$ and neutral $\mathrm{pH}$ conditions. 

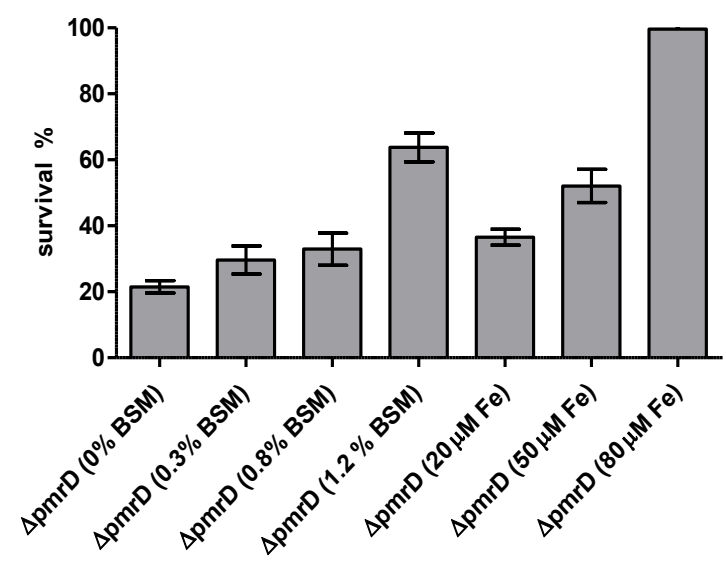

A

PMB treated
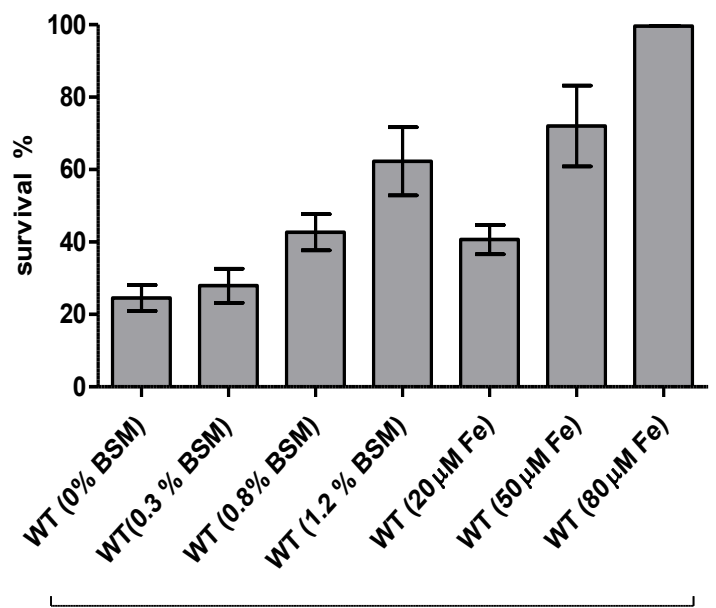

PMB treated

B

Figure 7 Pre-treatment of WT and pmrD mutants with increasing concentration of BSM and $\mathrm{Fe}^{3+}$ induce correspondingly increased survival: Survival after PMB treatment of EHEC 86-24 WT and pmrD mutants cultured in high $\mathrm{Mg}+2\left(10 \mathrm{mM} \mathrm{MgCl}_{2}\right)$ and neutral $\mathrm{pH}$ with increasing concentration of $\mathrm{BSM}$ and $\mathrm{Fe} 3+$. A) $p m r D$ mutant $\mathbf{B}) \mathrm{WT}$. Data bars represent means $\pm \mathrm{SEMs}, \mathrm{N}=3$.

\section{5 $\mathrm{BSM}$ and $\mathrm{Fe}^{3+}$ have no additive effect on $\mathrm{PMB}$ resistance}

When the two signals, $0.8 \% \mathrm{BSM}$ and $50 \mu \mathrm{M} \mathrm{FeSO}_{4}$ shown to induce partial PMB resistance (Figure $8 \mathrm{~A}$ and $\mathrm{B}$ ). When these inducing conditions were used in combination as the pre-treatment in another experiment, the survival rates still appear the same (Figure 8). In the absence of other activating signals, $\mathrm{BSM}$ and $\mathrm{Fe}^{3+}$ triggers $\mathrm{PMB}$ resistance but when combined, they fail to produce either an additive or synergistic effect. This could be explained that if $\mathrm{BSM}$ and $\mathrm{Fe}^{3+}$ compete for the same PmrB binding site. Previous work 
in our lab has shown that BSM-induced resistance is mediated through the iron-binding site on PmrB and therefore these results provide support for this interpretation. Consequently, it can be assumed when one signal is already activating PmrB, the other one is unable to bind or activate PmrB.

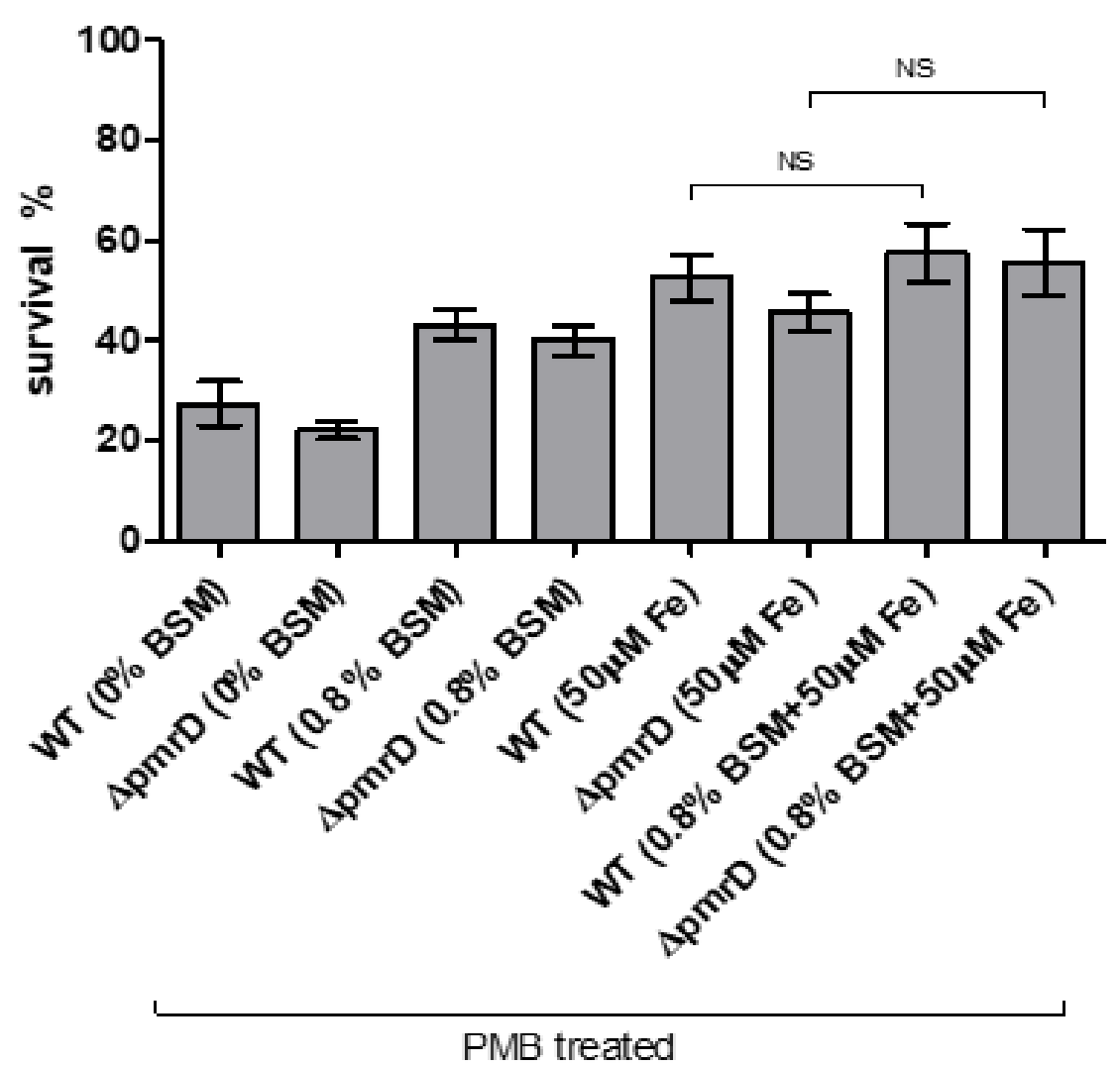

Figure 8 Combined pre-treatment with $0.8 \% \mathrm{BSM}$ and $50 \mu \mathrm{M} \mathrm{Fe}^{3+}$ signals has no additive effect on survival rate: Survival after PMB treatment of EHEC 86-24 WT and pmrD mutants cultured in high $\mathrm{Mg}^{+2}\left(10 \mathrm{mM} \mathrm{MgCl}_{2}\right)$ and neutral $\mathrm{pH}$ with different 
concentration of BSM and $\mathrm{Fe}^{3+}$. Data bars represent means \pm SEMs, $\mathrm{N}=3$. One-way ANOVA followed by Tukey's post-hoc test. * $\mathrm{P}<0.05$

\section{6 $\mathrm{BSM}$ and $\mathrm{Fe}^{3+}$ signal activate $\mathrm{PMB}$ resistance in a $\mathrm{PmrB}$ dependent fashion}

BSM- and $\mathrm{Fe}^{3+-}$ induced PMB resistance is fully dependent on $\mathrm{pmr} B$ as shown in Figure 9A and $\mathrm{B}$. Under high $\mathrm{Mg}$ and neutral $\mathrm{pH}$ (non-PhoPQ activating condition), PMB survival of WT grown in medium supplemented with $1.5 \% \mathrm{BSM}$ and $100 \mu \mathrm{M}$ Fe is significantly higher than the WT strain grown in non-supplemented medium. However, the survival of the pmrB mutant grown in medium supplemented with $1.5 \% \mathrm{BSM}$ and $100 \mu \mathrm{M}$ Fe is significantly decreased. BSM-mediated PMB resistance also appears to be dependent on phoP. PMB survival of phoP mutant grown in $1.5 \% \mathrm{BSM}$ is significantly lower than the WT strain grown in the same condition whereas survival rate of phoP mutant grown in $100 \mu \mathrm{M}$ Fe displays significantly higher survival but still lower than the WT strain grown in the same condition. These results suggest that under high $\mathrm{Mg}^{2+}$ and neutral $\mathrm{pH}$ conditions, BSM and Ferric iron-induced PMB resistance is fully dependent on $p m r B$ and at least partially dependent on phoP.

Under low $\mathrm{Mg}^{2+}$ neutral $\mathrm{pH}$ (PhoPQ activating condition), PMB survival rate of $\mathrm{pmrB}$ mutant is maintained but lower than the WT strain as shown in Figure 9 B. The survival 
rate of phoP mutant is significantly lower than the WT strain. Interestingly, survival rate of $p m r B$ mutant grown under low $\mathrm{Mg}^{+2}$ and high iron condition is significantly decreased than the survival rate of $p m r B$ mutant without $100 \mu \mathrm{M}$ iron signal. These results suggest that under low $\mathrm{Mg}^{+2}$ and neutral $\mathrm{pH}$ conditions, Ferric iron-induced resistance is still fully dependent on $p m r B$ and again partially dependent on $p h o P$. But interestingly, $p m r B$ is not required for $\mathrm{PMB}$ resistance in the absence of iron.
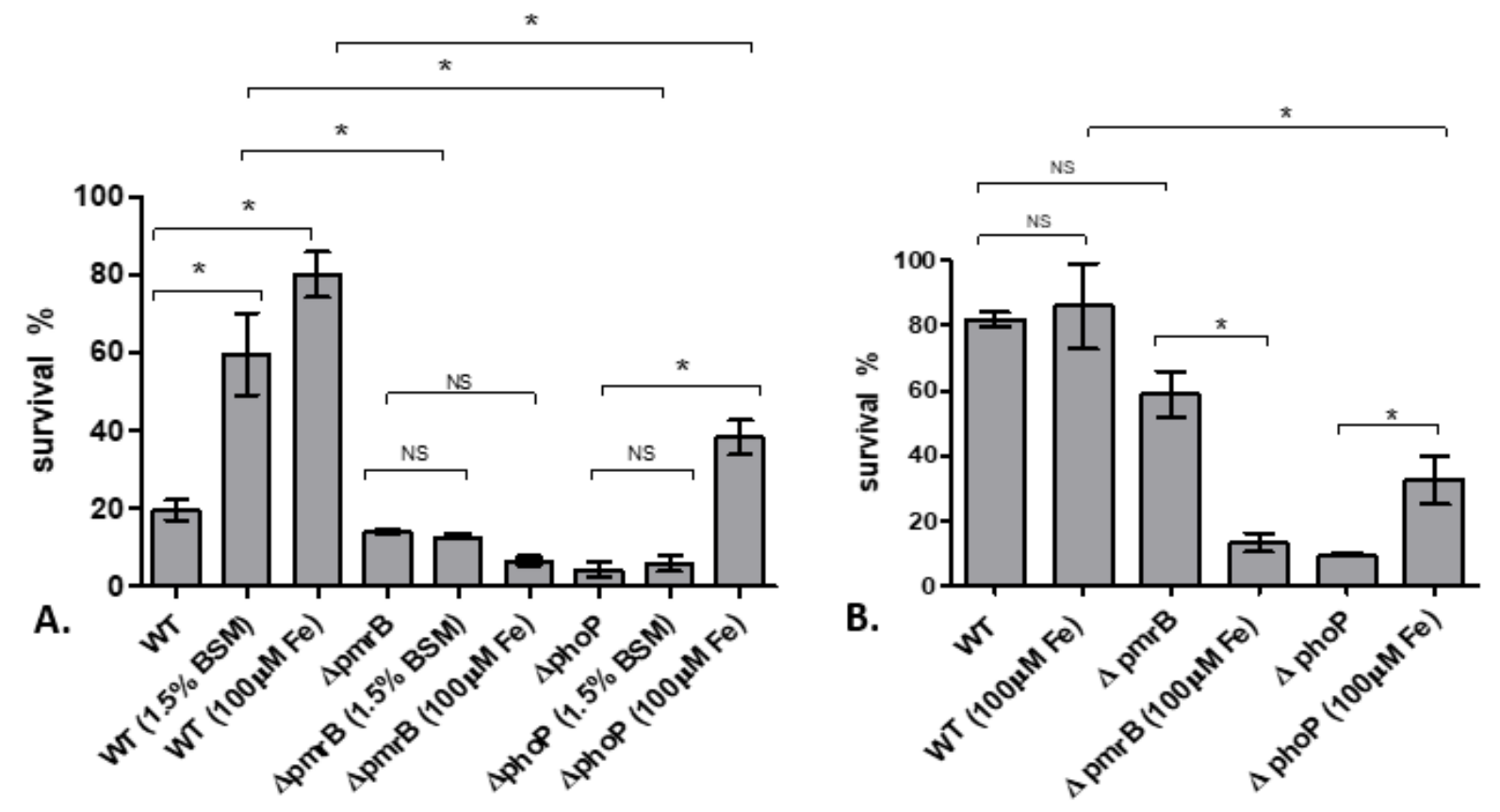

Figure 9 Survival rate after PMB treatment of EHEC WT, $\Delta p m r B$ and $\Delta p h o P$ : A)

Under high $\mathrm{Mg}^{+2}(10 \mathrm{mM} \mathrm{MgCl} 2)$ and $\mathrm{pH} 7.0$, B) Under low $\mathrm{Mg}^{+2}\left(10 \mu \mathrm{M} \mathrm{MgCl}_{2}\right)$ and neutral $\mathrm{pH}$ (7.0). Data bars represent means $\pm \mathrm{SEMs}, N=3$. One-way ANOVA followed by Tukey's post-hoc test. ${ }^{*} P<0.05$. 


\subsection{The activity of the pmrD promoter is influenced by numerous signals}

The $p m r D-g f p$ translational reporter plasmid was constructed, verified by DNA sequencing results and then transformed in pmrD mutant EHEC 86-24. GFP expression dynamics were tested by growing the fusion construct under both pmrD-activating and non-activating conditions as suggested by the previous experiments. In these experiments, GFP expression is considered a measure of $p m r D$ promoter activity. The $p m r D$-gfp reporter and control strain were grown in Synergy HTX fluorescent plate reader (Biotek) at $37^{\circ} \mathrm{C}$ under continuous shaking mode and monitored for $\mathrm{OD}_{600}$ and fluorescence for 14 hours in various conditions as indicated in the graph. Fluorescence activities ( $p m r D$ promoter activities) were expressed as a ratio of relative fluorescent unit (RFU) per number of cells (RFU/OD 600 ). Figure 10 shows the GFP expression as a measure of $p m r D$ promoter activity under various conditions. In order to understand the promoter activities, we compared the growth kinetics (Figure 10A) and $g f p$ fluorescence activities under defined media treatments (Figure $10 \mathrm{~B}$ and $\mathrm{C}$ ).

\subsubsection{The pmrD promoter is highly active under low Magnesium}

Promoter activity under high $\mathrm{Mg}^{+2}$ did not increase any time during 14 hours of GFP fluorescence monitoring, suggesting that high $\mathrm{Mg}^{+2}$ does not promotes $p m r D$ expression regardless of the presence of signals either BSM or $\mathrm{Fe}^{+3}$ present in the growth medium. 
$\operatorname{pmrD}$ activity is maximal in low $\mathrm{Mg}^{+2}$ and neutral $\mathrm{pH}$. When fluorescence was monitored for 14 hours, we observed that $p m r D$ promoter activity has a noticeable delay in GFP fluorescence. It takes approximately 4 hours to achieve the persistent rise in fluorescence. After 4 hours, promoter activity under low $\mathrm{Mg}^{+2}$ and neutral $\mathrm{pH}$ increases dramatically. When $g f p$ expression patterns were compared, the $p m r D$ promoter activity appears to be significantly higher under low $\mathrm{Mg}^{+2}$ at $\mathrm{pH} 7.0$ than under low $\mathrm{Mg}^{+2}$ at low $\mathrm{pH}$, or under low $\mathrm{Mg}^{+2}$, neutral $\mathrm{pH}$ with BSM and $\mathrm{Fe}^{3+}$ (Figure. $10 \mathrm{~B} / \mathrm{C}$ )

\subsubsection{The pmrD promoter activity repressed by $\mathrm{BSM}$ and $\mathrm{Fe}^{3+}$}

The $p m r D-g f p$ reporter and control strains were grown in Synergy HTX fluorescent plate reader (Biotek) at $37^{\circ} \mathrm{C}$ under continuous shaking mode and monitored for $\mathrm{OD}_{600}$ and fluorescence for 14 hours in various conditions. Promoter activity under BSM and $\mathrm{Fe}^{3+}$ signals appears to plateau out after 4 hours, suggesting $g f p$ expression is inhibited by these signals. The $p m r D$ promoter activity seems significantly repressed by high $\mathrm{Fe}^{3+}$ and $\mathrm{BSM}$ signal (Figure. $10 \mathrm{~B} / \mathrm{C}$ ). These signals which all activate PmrA/PmrB likely suppress the expression of $p m r D$ through the phospho-PmrA.

When $g f p$ expression patterns were compared, the $\operatorname{pmrD}$ promoter activity appears to be

significantly higher under low $\mathrm{Mg}^{+2}$ at $\mathrm{pH} 7.0$ but $\mathrm{pmrD}$ promoter activity seems significantly repressed by high $\mathrm{Fe}^{3+}$ and BSM signal (Figure $10 \mathrm{~B} / \mathrm{C}$ ). The fact that $p m r D$ 
is not expressed under high $\mathrm{Mg}^{+2}$ and in the presence of BSM (Figure 10B/C) supports the finding that BSM-induced PMB resistance is independent of $p m r D$.

\subsubsection{The pmrD promoter is repressed by low $\mathrm{pH}$}

The $\operatorname{pmrD}$ promoter activity seems significantly repressed by mildly low $\mathrm{pH}(\mathrm{pH} 5.8)$ as well (Figure $10 \mathrm{~B} / \mathrm{C}$ ). These signals which all activate $\mathrm{PmrA} / \mathrm{PmrB}$ likely suppress the expression of $p m r D$ through the phospho-PmrA. The fact that $p m r D$ is not expressed under

high $\mathrm{Mg}^{+2}$ and mildly low $\mathrm{pH}$ (Figure $10 \mathrm{~B} / \mathrm{C}$ ) supports the finding that low $\mathrm{pH}$-induced PMB resistance is independent of $p m r D$.

A.

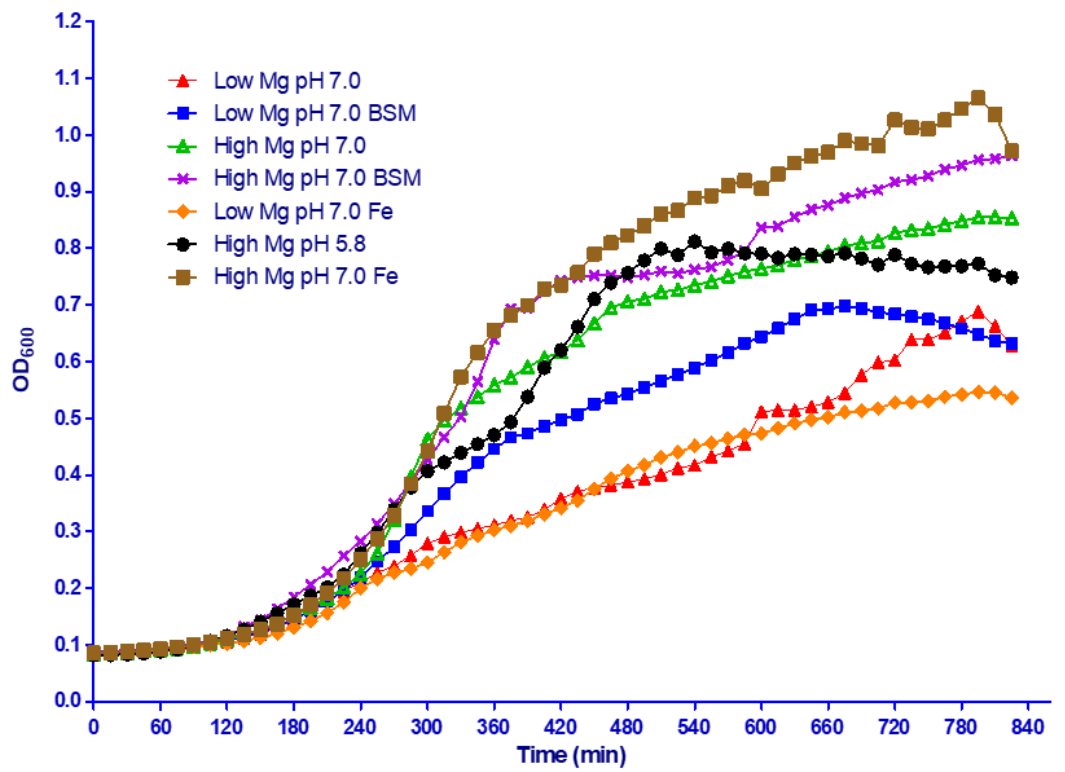




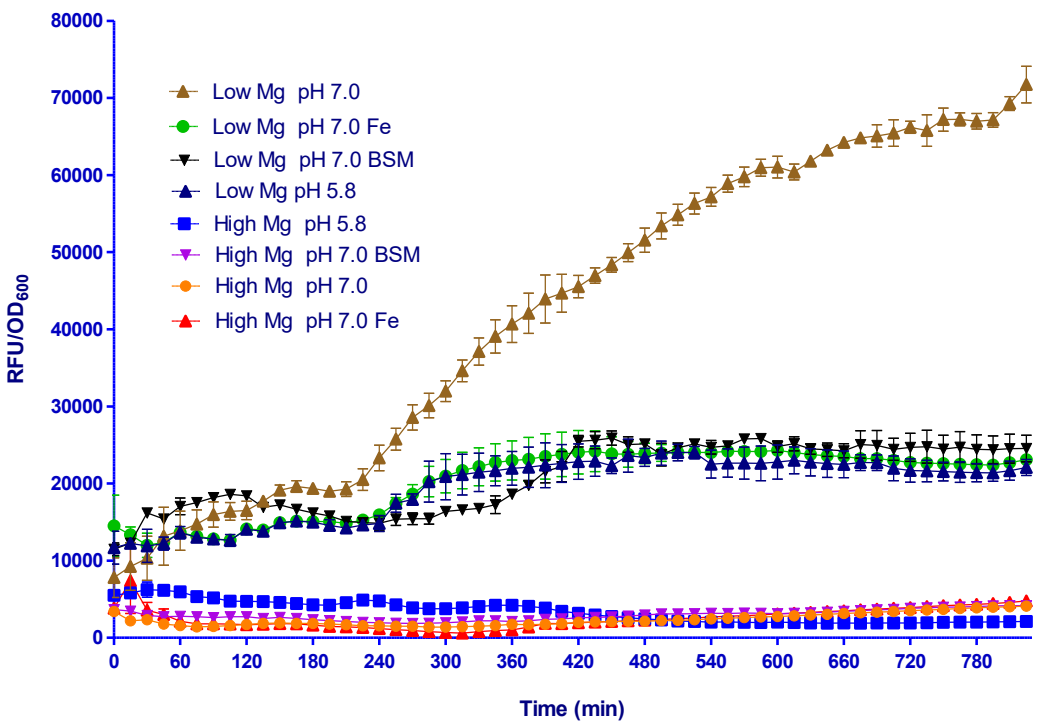

c.
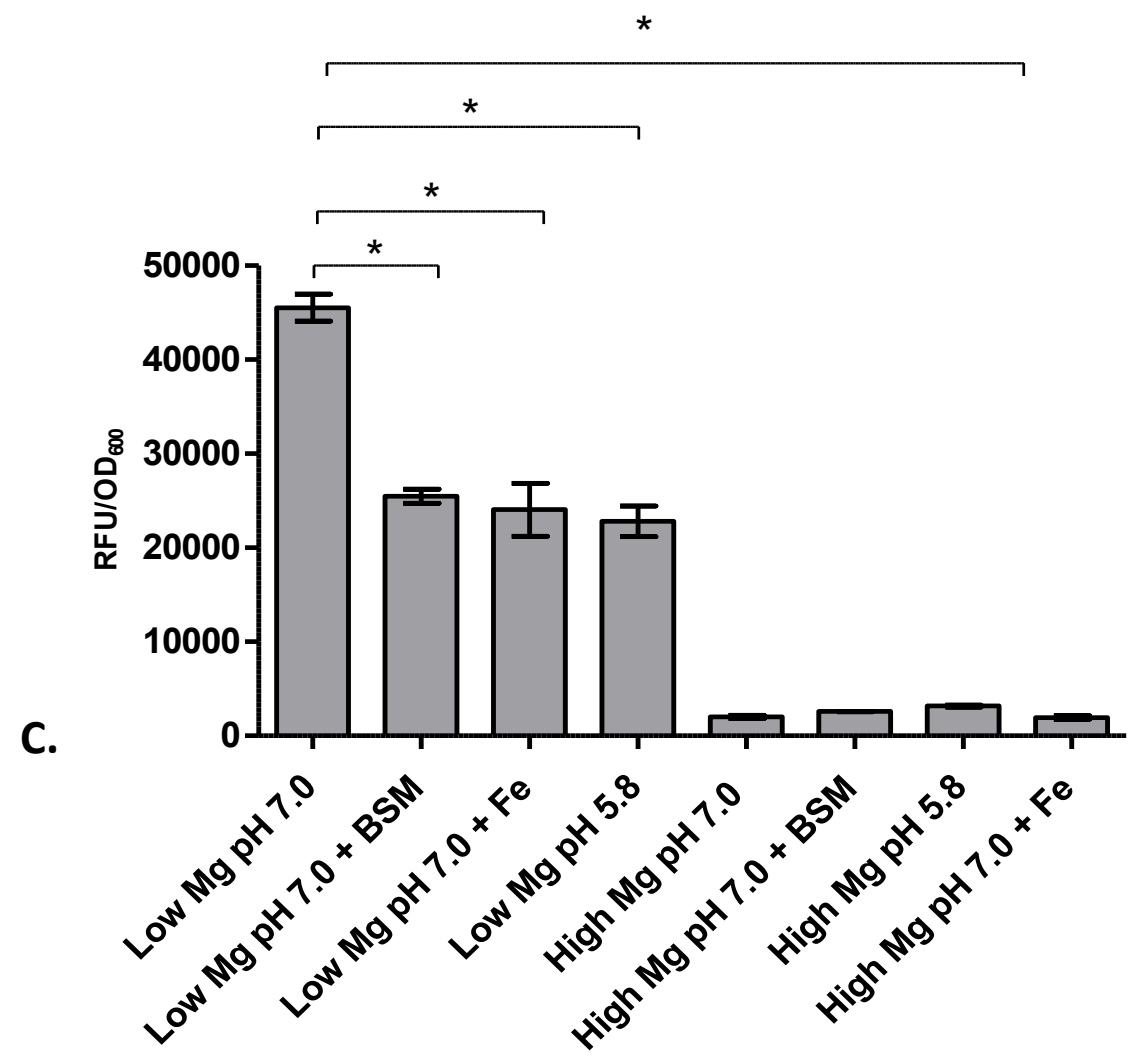
Figure $10 \mathrm{pmrD}$ promoter activity monitored under $\mathrm{low} \mathrm{Mg}^{+2}$ at neutral $\mathrm{pH}$ and measured the effect of signals such as low $\mathrm{pH}, 1.5 \% \mathrm{BSM}$ and high $\mathrm{Fe}^{3+}$ : A) Growth kinetics of $p m r D-g f p$ reporter strain (86-24ApmrD harboring TOPO plasmid with $g f p$ coding sequence under $p m r D$ native promoter) grown in high/ low $\mathrm{Mg}^{+2}$ with or without $\mathrm{BSM}$ or $\mathrm{Fe}^{3+}$. The $\mathrm{OD}_{600}$ of $g f p$ reporter strains grown in defined $(\mathrm{N}$-minimal) medium supplemented with $1.5 \% \mathrm{BSM}$ or $100 \mu \mathrm{M} \mathrm{FeSO}_{4}$ was recorded at the indicated time points and plotted over time for 14 hours. B) GFP expression presented in a relative fluorescent unit (RFU) as a function of growth $\left(\mathrm{OD}_{600}\right)$ over time. Fluorescent activities (pmrD promoter activities) were expressed as a ratio of relative fluorescent unit (RFU) per number of cells (RFU/OD 600$)$. C) GFP fluorescence ( $p m r D$ promoter activity) compared at the 7 hours' time point in defined conditions as mentioned in the Figure. Error bar represents the upper and lower limit of sd. N=3, One-way ANOVA followed by Tukey's post-hoc test. $* \mathrm{P}<0.05$.

\subsection{No interaction exists between BSM and PMB}

In order to detect potential synergistic or antagonistic interactions between the inducing signal, BSM and the killing cationic antimicrobial peptide, PMB used in the PMB resistance assay, we ran the synergy test between these two compounds in both high $\mathrm{Mg}^{+2}$ neutral $\mathrm{pH}$ and low $\mathrm{Mg}^{+2}$-neutral $\mathrm{pH} \mathrm{N}$-minimal media.

Synergy between BSM and PMB was tested using the checkerboard method as described by CLSI (Clinical Laboratory Standard Institute, 2007). The fractional inhibitory 
concentrations for interactions between BSM and PMB were determined. No synergistic or antagonistic interaction was detected between BSM and PMB in both high $\mathrm{Mg}^{+2}$ - neutral $\mathrm{pH}$ and low $\mathrm{Mg}^{+2}$-neutral $\mathrm{pH} \mathrm{N}$-minimal media as shown in Table 4. Therefore, we can conclude that PMB killing carried out with 2, 4, $8 \mu \mathrm{g} / \mathrm{ml}$ PMB does not seem to be influenced positively or negatively by the antimicrobial properties of $1.5 \%$ BSM. Additionally, in order to remove any kind of effect associated with the use of $1.5 \%$ BSM during the pre-treatment stage of the culture, cells were washed three times before the killing assays.

The total FIC values were interpreted as follows:

\begin{tabular}{|c|c|}
\hline Synergistic & $\leq 0.5$ \\
\hline Indifferent & $>1.0-4.0$ \\
\hline Antagonistic & $>4.0$ \\
\hline
\end{tabular}

Checkerboard assay were performed as described by CLSI on 96 microwell plate on logphase bacterial suspension prepared in respective medium as indicated in the result table. Plate readings were done with HTX Microplate Reader (Biotek) after 18 hours' incubation at $37^{\circ} \mathrm{C}$. 
Table 4 Checkerboard assay results

\begin{tabular}{|c|c|c|}
\hline $\begin{array}{c}\text { Checkerboard assay } \\
\text { condition }\end{array}$ & $\begin{array}{c}\text { Calculated TFIC (FIC of } \\
\text { BSM + FIC of PMB) }\end{array}$ & Interpretation \\
\hline $\mathrm{N}$-minimal low $\mathrm{Mg}^{+2} \mathrm{pH} 7$ & $=1.06$ & Indifferent \\
\hline $\mathrm{N}$-minimal high $\mathrm{Mg}^{+2} \mathrm{pH} 7$ & $=1.25$ & Indifferent \\
\hline
\end{tabular}




\section{Discussion}

The gram-negative bacterial outer membrane is an asymmetric bilayer composed of an inner leaflet of phospholipids and an outer leaflet of lipopolysaccharide. Lipid A appears to be highly conserved structure of pathogenic bacteria and therefor serves as the critical component if LPS structure (Raetz et al. 2007). It not only serves as the toxic component of bacterial cell to animal host but also serves as means of survival tool. Lipid A is readily modifiable at its 1'- and 4' positions, where covalent modifications can be made. These modifications have been shown to enhance bacterial fitness and survival in harsh host or non-host environmental conditions and to escape killing by host defenses systems (Matsuura 2013).

A comprehensive understanding of survival strategies and virulence mechanisms of EHEC could help design an effective control strategy for EHEC infection. In order to establish itself as a successful pathogen, EHEC has the ability to evade host defense mechanisms and survive within the human gastrointestinal tract. The gastrointestinal tract which is a naturally inhospitable environment to most of the microorganisms due to the presence of high acidity, digestive enzymes and bile salt mixture in various anatomical niches within the GI tract. EHEC are exposed to these conditions during their transit through the GI tract. Instead of being killed by these environments, EHEC utilizes these environments as the signals for upregulation of mechanisms that help them to evade the attack by host defenses including cationic antimicrobial peptides likely to be encountered in the subsequent part of 
the intestine. It is still not fully understood how EHEC manages to overcome the effect of these environments and shows increased CAMP resistance. In this study, we attempted to understand EHEC responses to selected chemical and biochemical cues likely present in the gastrointestinal tract environment in terms of resistance to a classical cationic antimicrobial peptide, PMB. Our purpose was to look at role of signal transduction pathways, particularly the PmrD connector protein, and how the main host environmental conditions such as high acidity, high iron and bile salt mixtures are used as signals to mount the CAMP resistance ability.

To investigate the effect of limiting $\mathrm{Mg}^{2+}$ as a signal for lipopolysaccharide modification, we determined the PMB resistance after growth in the presence of low $\mathrm{Mg}^{2+}$. The twocomponent regulatory system $\mathrm{PhoP} / \mathrm{PhoQ}$ has been shown to be responsible for low $\mathrm{Mg}^{2+}$ sensing in many gram-negative bacteria such as in Salmonella and several other enteric bacteria (Luo et al., 2010, Kato, Latifi, \& Groisman, 2003). In high $\mathrm{Mg}^{2+}$ condition PhoQ kinase activity remains repressed due to divalent cation salt-bridge formation between periplasmic domain of PhoQ and inner membrane. Under low $\mathrm{Mg}^{2+}$ condition, this saltbridge is disrupted causing conformational change that leads to PhoQ activation. Activated PhoQ then promotes phosphorylation of PhoP and subsequently results in increased expression of the target genes. PhoP-regulated gene products are involved in lipopolysaccharide modifications and promote growth in low $\mathrm{Mg}^{2+}$ environments. We used this low $\mathrm{Mg}^{+2}$ condition, a well-established PhoQ-activating condition for Salmonella to study the role of EHEC PmrD in LPS modification and CAMP resistance. While the role 
of Salmonella PmrD in LPS modification is already clear, there is still uncertainty about whether EHEC PmrD can transduce the low $\mathrm{Mg}^{+2}$-induced signal to the master regulators of LPS modification, PmrA, as many pmrA-regulated gene products are LPS modifying enzymes (Gunn 2001). We found the exposure of EHEC to the low $\mathrm{Mg}^{2+}$ condition enhances PMB resistance in a $p m r D$ - and $p h o P$-dependent manner. Secondly, $p m r D$ promoter activity was also dramatically increased in the low $\mathrm{Mg}^{+2}$ condition. GFP fluorescence starts to rise after 4 hours of growth in this medium. This type of delayed response is normal in the connector-mediated pathway since it may take extra time to process the signals (Kato et al. 2007). Another reason for this delayed response could be explained by the fact that bacterial response through protein expression is low in lag phase and high in exponential phase. This observation tells us that even though during the evolutionary race Salmonella and EHEC diverged from a common ancestor some 100 million years ago and there is only $55 \%$ identity in $p m r D$ sequence (Winfield and Groisman 2004), EHEC still retains the functionally equivalent PmrD.

EHEC has the extraordinary tolerance ability to low $\mathrm{pH}$ as demonstrated by its survival at $\mathrm{pH}$ levels as low as $2 \cdot 5$ for $2 \mathrm{~h}$ (House et al. 2009). To investigate whether low $\mathrm{pH}$ is related to the ability to resist cationic antimicrobial peptide PMB, we determined the PMB resistance after culturing EHEC 86-24 in the presence of low $\mathrm{pH}$. We found that both WT and $p m r D$ mutant strains were able to grow and showed increased resistance to PMB in the presence of low $\mathrm{pH}$. The PMB survival of $p m r D$ mutant was not impaired in the presence of mildly low $\mathrm{pH}$. This observation suggests that EHEC can easily adapt to this stressful 
environment of low $\mathrm{pH}$ and not only resume growth in this condition but also uses the low $\mathrm{pH}$ as the signal to improve its CAMP resistance without the PmrD-mediated PhoPQ two component signal transduction pathway. Using the $\operatorname{pmr} D$ promoter analysis assay, we were able to observe the genetic basis of this phenotype. Exposure to low $\mathrm{pH}$ resulted in minimal pmrD promoter activity. This result substantiates the results of the killing assay which showed that $\mathrm{pH}$-induced PMB resistance in EHEC was independent of $p m r D$. Similar research in Salmonella typhimurium has shown that mildly low $\mathrm{pH}(\mathrm{pH} 5.8)$ is sensed by the sensor domain located in PhoQ (Ohl and Miller 2001) as well as in PmrB (Perez \& Groisman, 2007). Based on our data that inactivation of $p m r B$ gene significantly decrease the PMB survival rate of EHEC grown in low $\mathrm{pH}$ condition suggest that EHEC prefers to use the PmrA/PmrB two component system for low $\mathrm{pH}$ sensing, in contrast to Salmonella typhimurium which can use both two-component system. Additionally, our study also revealed that exposure to low $\mathrm{pH}$ represses the $\operatorname{pmrD}$ expression under low $\mathrm{Mg}^{+2}$ conditions. $\operatorname{pmrD}$ expression is usually very high under low $\mathrm{Mg}^{2+}$. However, GFP fluorescence is significantly decreased when grown in the presence of $\mathrm{pH}$ 5.8. Due to the fact that GFPmut3 fluorescence intensity does not decrease significantly at this $\mathrm{pH}$ (Cheng et al., 2017), suggests that $p m r D$ expression may be repressed by low $\mathrm{pH}$ signal under low $\mathrm{Mg}^{2+}$ condition. EHEC may adopt this strategy when it has enough phosphorylated PmrA to promote lipid A modification and confer CAMP resistance. Some food products, especially ones with acidic preservatives and some fermented food products may therefore support the survival of EHEC and may promote infection. 
Bile is a complex mixture secreted in the duodenum which has membrane disrupting and DNA damaging effects on microorganism. To establish infection an enteric pathogen must resist the effect of bile salt mixture and be able to grow in physiologically relevant concentrations of BSM. Even though it has been known that many gram-negative bacteria can resist bile and salt mixture to some extent, but it is still unclear whether exposure to it induces PMB resistance in enteric pathogens. In our experiments, we found that EHEC 8624 grew with some level of inhibition at $1.5 \%$ BSM. In the PMB resistance assays, EHEC 86-24 grown at 1.5\% BSM until log phase had significantly higher PMB resistance than the untreated strain. Wild type EHEC and $p m r D$ mutant when exposed to the same concentration of BSM, showed similar PMB resistance pattern under neutral $\mathrm{pH}$ and nonlimiting $\mathrm{Mg}^{+2}$. This observation shows that the BSM-mediated resistance does not require PmrD protein, suggesting that BSM signal is directly sensed by PmrAB two-component system. The promoter activity analysis showed no or very minimal $p m r D$ promoter activities for EHEC grown under high $\mathrm{Mg}^{+2}$, neutral $\mathrm{pH}$ in $1.5 \% \mathrm{BSM}$. This supports the conclusion drawn from the PMB killing assay data that BSM-mediated cationic antimicrobial resistance does not require PmrD. Interestingly, exposure to BSM represses the $p m r D$ expression when $1.5 \% \mathrm{BSM}$ is introduced into the low $\mathrm{Mg}^{+2}$ condition which suggests that BSM signal is sensed directly by $\mathrm{PmrA} / \mathrm{PmrB}$ two-component system. Bile salts have been shown to trigger virulence factor expression in many gram-negative bacteria like Salmonella, Vibrios and Campylobacter (Merritt and Donaldson 2009). We previously reported that $p m r A B$ and the $p m r A$-activated operon $p m r H F I J K L M$ and $u g d$ are all upregulated in EHEC when exposed to BSM (Kus et al. 2011). The PMB resistance and promoter analysis results from this study clearly suggest that the bile salt mixture is sensed 
though the PmrAB two component system and that the PMB resistance is $p m r B$-dependent. This agrees with the findings of the microarray analysis (Kus et al. 2011). The interaction between bile salt mixture and a bacterial sensor kinase may be physiologically most efficient for activating protective mechanisms like lipid A modifications on the outer surface. Transducing the signal through connector mediated pathways appears to be less efficient than the direct interaction of the BSM with PmrB sensor kinase.

We also investigated the ability of $\mathrm{Fe}^{3+}$ cations to activate CAMP resistance in EHEC. For people on a standard diet, the stomach and initial part of intestine may provide a relatively iron rich environment, typically in the range of 29 to $733 \mu \mathrm{M}$ (Simpson and Peters 1990). Our results showed higher PMB survival rates for iron-treated EHEC compared to untreated EHEC. Inactivating the $p m r D$ gene did not affect the overall PMB survival rates of EHEC under high as well as under low $\mathrm{Mg}^{2+}$ condition when exposed to high iron condition. These results suggest that an iron rich environment triggers a protective response in EHEC where $\mathrm{Fe}^{3+}$-induced CAMP resistance is mediated though PmrA/PmrB two-component system. This result was confirmed by the findings that very minimal $p m r D$ promoter activity was observed in iron treated EHEC. The experimental finding that introducing iron in low $\mathrm{Mg}^{+2}$ conditions inhibits the $p m r D$ promoter activity provides evidence for a feedback control loop between the PmrAB and PhoPQ. These findings are consistent with previous findings that the periplasmic domain of PmrB has an iron binding motif in Salmonella typhimurium, Escherichia coli (K-12) and Klebsiella pneumoniae (Chen and Groisman 2013). Furthermore, all of these bacteria also have functional PmrD. 
PmrAB has been reported to serve as an important regulator of LPS modification and is critical for $\mathrm{Fe}^{3+}$ induced resistance in Salmonella. This suggests that the iron sensing ability is highly conserved among enterobacteriaceae and serves as the regulator of virulence in enteric pathogens within the host. This response helps bacteria survive where iron concentrations are high.

In order to understand the details how BSM and high iron signals are sensed, we performed PMB killing on WT, $p m r B$ mutant and $p h o P$ mutant in various conditions. The fact that $\mathrm{BSM}$ and $\mathrm{Fe}^{3+-}$ induced $\mathrm{PMB}$ resistance increases on WT strains but is lost in $p m r B$ mutant strongly suggests that BSM and $\mathrm{Fe}^{3+}$ is sensed mainly though PmrB. Under high $\mathrm{Mg}^{+2}(10$ $\mathrm{mM} \mathrm{MgCl} 2$ ) and $\mathrm{pH} 7.0$ condition, BSM mediated PMB resistance is dependent on $p m r B$ as well as on phoP. It appears that for the PMB resistance due to BSM signal under high $\mathrm{Mg}^{+2}$ and neutral $\mathrm{pH}$ phoP-activated genes are necessary. PhoP-activated gene products have been reported in mediating the bile resistance in Salmonella typhimurium (Van Velkinburgh and Gunn 1999). But this would be the first observation that BSM-mediated PMB resistance in EHEC is also dependent on phoP gene.

Iron mediated PMB resistance is fully dependent on $p m r B$ and partially dependent on $p h o P$. Interestingly, inactivation of $p m r B$ gene severely impairs the PMB survival rate of EHEC under low $\mathrm{Mg}^{+2}\left(10 \mu \mathrm{M} \mathrm{MgCl}_{2}\right)$ and neutral $\mathrm{pH}(7.0)$ when supplemented with extra iron. It appears that $p m r B$ mutant under this condition fails to regulate the modifications in the 
outer membrane which is supposed to protect EHEC from toxic metal ions as well as from the PMB.

Taken together, the results from this work demonstrate that EHEC uses PmrAB and PhoPQ to monitor its surroundings, including $\mathrm{pH}$, divalent cation, iron and $\mathrm{BSM}$ to direct its survival and virulence. Under PhoPQ activating condition (low $\mathrm{Mg}^{+2}$ condition) where pmrA-dependent lipid A modifying enzymes are already activated, PmrB-activating signals do not act additively. Instead, $\mathrm{BSM}, \mathrm{Fe}^{+3}$ and low $\mathrm{pH}$ repress the excessive activation of lipid A modifying enzymes. This is how EHEC PhoPQ and PmrAB two-component system stimulate the optimal level of lipid A modifications but prevent the potential detrimental effects of excessive LPS modification. In future studies, it would be important to look at another relevant signal the CAMP itself. It can serve as activation signals for PhoQ for LPS modification in enteric pathogens (Bader, Navarre et al. 2003; Bader, Sanowar et al. 2005). In summary, exposure to low $\mathrm{Mg}^{+2}$ promotes CAMP resistance by a mechanism that requires the PhoPQ two-component system and PmrD. However, the PhoPQ system and PmrD are not necessary for the low $\mathrm{pH}$, bile salt mixture and iron-mediated CAMP resistance in EHEC, at least under nonlimiting $\mathrm{Mg}^{2+}$ conditions. However, under limiting $\mathrm{Mg}^{2+}$ conditions, bile salt mixture and iron-induced CAMP resistance have a more complex molecular mechanism. 


\section{Summary and significance}

Gram-negative bacteria use two-component regulatory systems, including PmrAB and PhoPQ to sense and respond to environmental signals by modifying their outmost layer to adapt to the diverse environments that they encounter. Studies on the regulatory architecture of two-component regulatory systems in the related pathogen, Salmonella, have revealed that PmrA, the response regulator of PmrAB system can be activated either by its own sensor domain, $\mathrm{PmrB}$ or by a non-cognate response regulator, PhoP, the response regulator of another two-component regulatory system, PhoPQ. The PMB resistant protein D (PmrD), is believed to establish the connection between PhoPQ and PmrAB system. This connectivity appears to serve as a critical step in sensing and integrating multiple signals for pathogen's own increased fitness and survival in some enteric pathogens (Winfield and Groisman 2004).

This project aimed to investigate the role of EHEC $p m r D$ in CAMP resistance induced in a variety of environmental signals. Our results indicate that low $\mathrm{Mg}^{2+}$ triggers the $\mathrm{pmrD}$ expression and subsequently increases the resistance to CAMPS, as tested by PMB resistance assay. When $p m r D$ is inactivated, EHEC resistance to CAMP is significantly reduced. This result suggests that like Salmonella typhimurium, EHEC PmrD connects the signal sensed by PhoPQ and passed to PmrAB system for coordinated protective modifications in bacterial outer layer. 
To understand how EHEC responds to low $\mathrm{pH}$, bile salt mixture and iron. Some of the most common environmental signals likely to be encountered during the transit through human gastro-intestinal tract, we used N-minimal medium supplemented with appropriate signals representative of the enteric environments. For example, $1.5 \%$ BSM pre-treatment condition mimics duodenum and small intestine environment, high iron and low $\mathrm{pH}$ pretreatment is representative of gastric environment. High iron condition may also represent the natural surface water and soil as well as some food products since iron is a very abundant element in the nature. Our result indicates that BSM and iron serve as potent intestinal cues for EHEC survival against CAMPs. $1.5 \%$ BSM and $100 \mathrm{uM} \mathrm{FeSO}_{4}$-induced PMB resistance do not require PmrD. Like Salmonella typhimurium, our result indicates that mildly low $\mathrm{pH}$ is also an intestinal cue for EHEC survival to PMB but unlike Salmonella typhimurium it does not appear to be sensed by PhoPQ but rather is dependent on PmrB and PhoP. The presence of either $1.5 \% \mathrm{BSM}$ or $100 \mathrm{uM} \mathrm{Fe}^{3+}$ appear to suppress pmrD expression which suggest that iron and BSM-mediated pathway inhibits the expression of $p m r D$ through feedback mechanism as depicted in the model of regulation of PMB resistance in EHEC 86-24 in Figure 11.

We assessed the EHEC phenotypic responses to various signals in various in-vitro conditions by PMB resistance assays. These results are logically backed up by $p m r D$ promoter activity measurements. We constructed the $p m r D-g f p$ reporter strains and carried 
out $g f p$ expression analysis in those conditions in which we conducted PMB resistance assays.

By our results, we noted that EHEC not only survives the challenges of these host factors but also exploits them to manage protective outer layer and evade killing by host cationic antimicrobial peptides (CAMPs). It helps us to understand how efficiently engineered their signaling network in enteric pathogen. The absence of $p m r D$ gene in pathogens like $C$. rodentium and $Y$. pestis still permits these pathogens to sense and respond to these types of signals. In general, our study contributes to our understanding how various signals are sensed and used by enteric pathogens to survive and enhance virulence.

TCRSs are signal transduction pathways unique to prokaryotes. Targeting these TCRS proteins may emerge as an effective strategy to control EHEC and related foodborne pathogens. The knowledge obtained during this study will contribute to the understanding of the action of TCSs in enterobacteriaceae, as well as their contribution in the survival mechanisms adopted by these types of microorganism in food or/and food processing and storage environment. 


\section{Model of regulation of PMB resistance in EHEC 86-24}

Figure 11 and 12 represent mechanistic models how EHEC 86-24 could regulate PMB resistance.

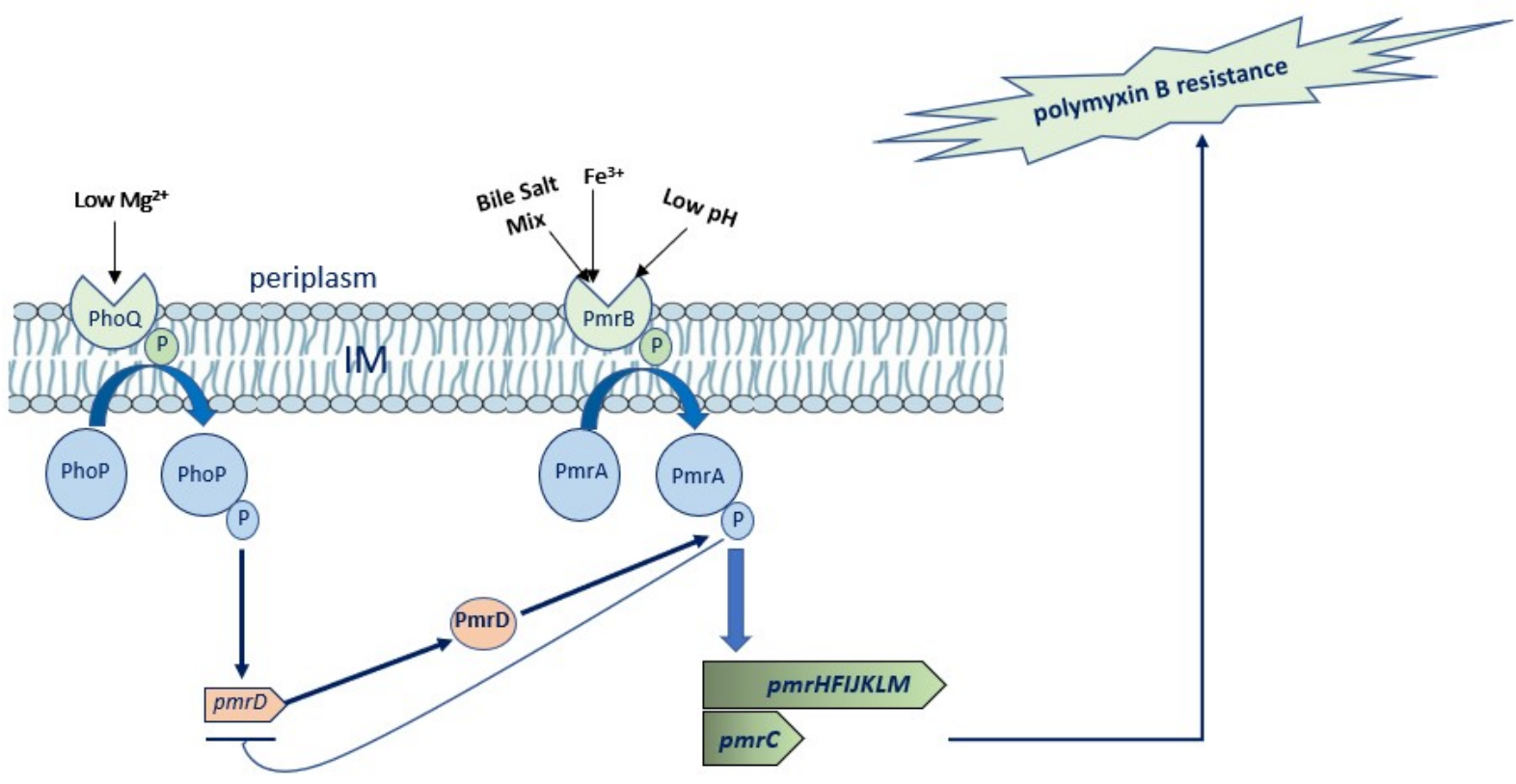

Figure 11 Model of regulation of PMB resistance under low $\mathrm{Mg}^{2+}$ in EHEC 86-24:

Low $\mathrm{Mg}^{2+}\left(10 \mu \mathrm{M} \mathrm{MgCl}_{2}\right)$ condition is sensed by inner membrane bound sensor kinase PhoQ which autophosphorylates and then transfers the phosphoryl group to PhoP, PhoP$\mathrm{P}$, an activated transcription factor which promotes transcription of the $p m r D$ gene. The PmrD protein then binds to phospho-PmrA, a response regulator of another two-component system, PmrA/PmrB system. PmrD blocks dephosphorylation of PmrA by sensor kinase PmrB, allowing continued transcription of $p m r H F I J K L M$ and $p m r C$, a major regulator of lipid A modification system. In the same way, sensor kinase PmrB when activated directly by high $\mathrm{Fe}^{+3}\left(100 \mu \mathrm{M} \mathrm{FeSO}_{4}\right)$ or low $\mathrm{pH}$ (5.8) promotes the phosphorylated state of the 
response regulator, PmrA which leads to the transcription of pmrHFIJKLM and pmrC. Excessive amount of PmrA-P represses transcription of the $p m r D$ gene, thus establishing a negative feedback loop regulating pmrD expression.

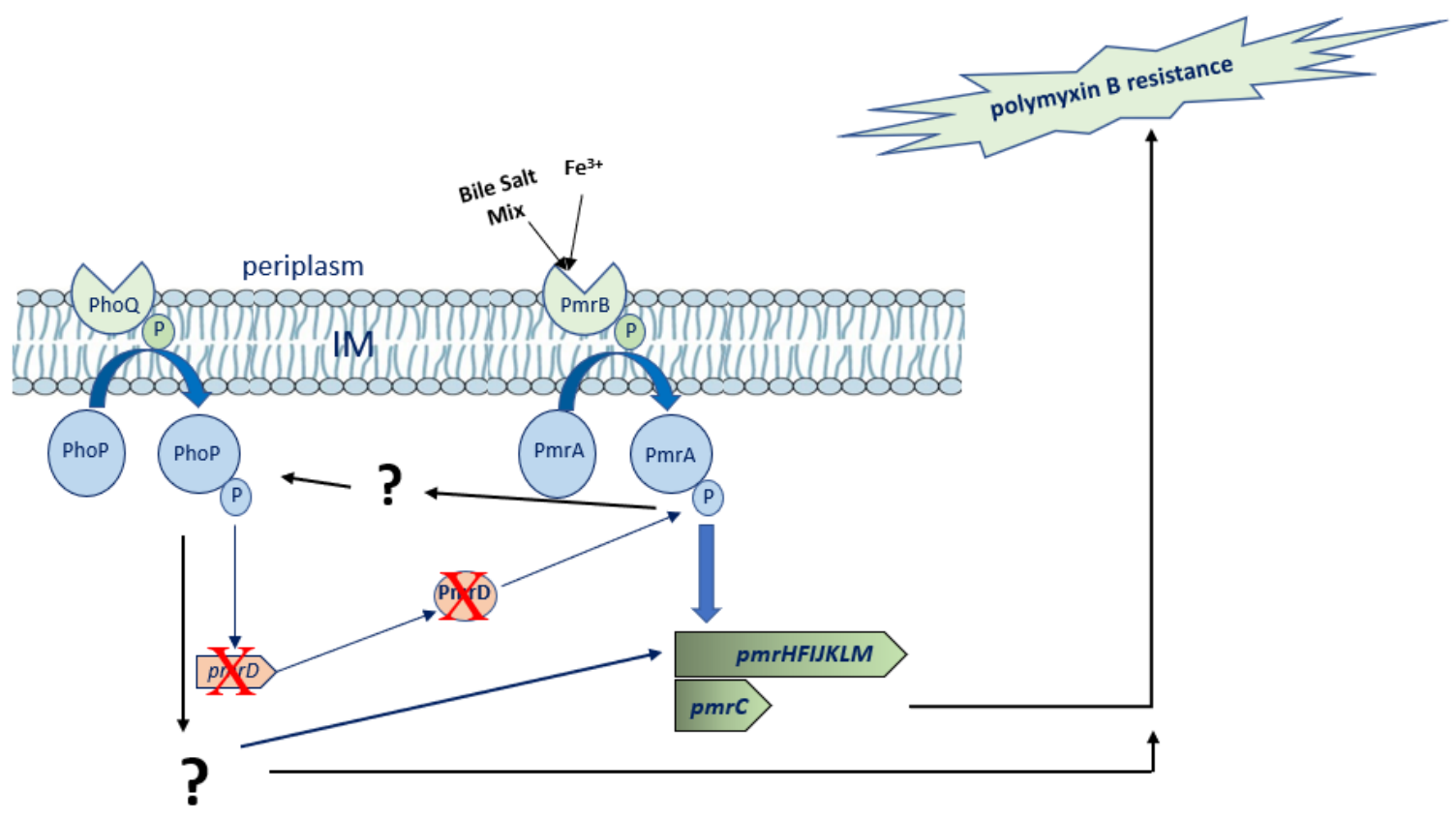

Figure 12 Model of regulation of PMB resistance under high $\mathrm{Mg}^{2+}$ and neutral $\mathrm{pH}$ in

EHEC 86-24: Inner membrane bound sensor kinase $\mathrm{PmrB}$ when activated by high $\mathrm{Fe}^{+3}$ $\left(100 \mu \mathrm{M} \mathrm{FeSO}_{4}\right)$ or BSM, promotes the phosphorylated state of the response regulator, PmrA, a DNA binding transcription factor. Activated PmrA (PmrA-P) then leads to transcription of pmrHFIJKLM and $p m r C$. Also, BSM-mediated PMB resistance is fully dependent on $p h o P$ by unknown connector proteins. Iron-mediated PMB resistance is also partially dependent on phoP. 
Bacterial two-component connector proteins may promote activation of both response regulators and sensor kinases. For example, EHEC PmrD connects the response regulator PhoP to response regulators of another two-component system, PmrA as demonstrated in this work and by many others in other members of enterobacteriaceae family. In the same way, SafA a connector protein from E. coli connects the response regulator (EvgA) of EvgA/EvgS system to the sensor kinase (PhoQ) of PhoP/PhoQ system (Eguchi et al. 2012). Therefore, we propose additional layer of interconnection between PmrAB and PhoPQ via small connector proteins might exist. The question marks illustrate potential spot for unknown connector protein which connects the signals activated by BSM and iron to PhoP and then to the appropriate points which then leads to expression of genes involved in outer membrane modification in EHEC. 


\section{Future directions}

We studied the phenotypic characteristics PMB resistance in response to selected individual and combined intestinal cues. It is clear that low $\mathrm{Mg}^{+2}$ and low $\mathrm{pH}$ induced conditions trigger the $p m r A$-regulated genes in many gram-negative bacteria by lipid A modification. The major cationic residues produced as a result of this type of signals are Laminoarabinose and phosphoethanolamine. When added to the lipid A moiety of LPS, they neutralize the negative charge on the bacterial surface and thus prevent the binding of positively charged human CAMPs.

The BSM-mediated EHEC PMB resistance mechanism is gradually unfolding in our lab. We know it is pmrAB and arnT dependent and now we know that at high $\mathrm{Mg}^{+2}$ and neutral $\mathrm{pH}$, it is independent of $p m r D$ but dependent on $p h o P$. We also know that it is swamped by low $\mathrm{Mg}^{+2}$ induction. We do not know which individual bile salts are the most effective in job. Therefore, the immediate further step is to perform killing assay with individual bile salts.

We know that lipid A is highly modifiable structure in gram-negative bacteria. To explore the molecular basis behind the PMB resistance due to BSM, analyze lipid A chemical profile by matrix assisted lase desorption/ionization-time of flight (MALDI-TOF) on 
BSM-induced EHEC cells. This assay would reveal the chemical moiety added to lipid A structure as a result of BSM exposure.

In this study we focused on $p m r D$, which connects the two major two-component system pathways. We also discovered BSM-mediated PMB resistance still appears to be dependent on phoP. To get the detailed insight into EHEC response to BSM and cross talk between these pathways or potentially others, it is important to further investigate interconnectivity between the response regulators and sensor kinase or vice versa. We can use genomic and proteomic approach to investigate this question. Briefly, we need to identify twocomponent proteins most impacted in BSM-treated EHEC, trace down the genes, generate mutants and look PMB resistance phenotype or gene expression responses.

Finally, PMB used in this study as a classical CAMP is not a human cationic antimicrobial peptide. It would be more relevant if we perform the killing assays with CAMPs of mammalian origin such as HD-5, HBD-1, HBD-2 and LL-37. 


\section{Appendices}

Additional details of protocols used in the work.

\section{A) Killing assay protocol for $1.5 \%$ BSM condition}

To assess the \% survival of EHEC 86-24 to Polymyxin B (2 ug/ml) induced under Nminimal medium (NM) with high $\mathrm{Mg}$ and Neutral $\mathrm{pH}+0 \%$ bile salt mix (BSM) and $\mathrm{NM}$ with high $\mathrm{Mg}$ and Neutral $\mathrm{pH}+1.5 \%$ BSM.

Day 1

$\mathrm{O} / \mathrm{N}$ culture

1. Prepare $20 \% \mathrm{BSM}$ solution and filter sterilize using $0.22 \mu \mathrm{m}$ membrane filter and syringe.

2. Prepare overnight samples of untreated and $1.5 \%$ bile salt mixture (BSM) treated cultures using a total volume of $5 \mathrm{~mL}$ in $10 \mathrm{~mL}$ round bottom culture tubes

a. Untreated $\rightarrow$ Prepare $5 \mathrm{ml} \mathrm{NM}$ with high $\mathrm{Mg}$ buffered at $\mathrm{pH} 7.0$ (No BSM)

b. $1.5 \%$ BSM treated $\rightarrow$ Prepare $5 \mathrm{ml} \mathrm{1.5 \%} \mathrm{BSM} \mathrm{in} \mathrm{NM} \mathrm{with} \mathrm{high} \mathrm{Mg}$ buffered at neutral $\mathrm{pH}$ and mix well (4.625 $\mathrm{ml} \mathrm{NM}$ and $0.375 \mathrm{ml}$ 20\% BSM)

3. Inoculate a single colony from recent EHEC 86-24 plate.

4. Incubate at $37^{\circ} \mathrm{C} \mathrm{O} / \mathrm{N}$ on a shaker.

Day 2

5. Read $\mathrm{OD}_{600}$ of overnight cultures.

6. Repeat $\# 1,2$ to prepare media for subcultures with a total volume of $5 \mathrm{~mL}$ in 10 $\mathrm{mL}$ round bottom culture tubes.

7. Inoculate $0 \% \mathrm{BSM}-\mathrm{NM}$ and $1.5 \% \mathrm{BSM}-\mathrm{NM}$ tubes with respective cultures $60 \mu \mathrm{L}$ and $120 \mu \mathrm{L}$ respectively from the $\mathrm{O} / \mathrm{N}$ culture. 
8. Incubate at $37^{\circ} \mathrm{C}$ on a shaker for $3-4$ hours and monitor OD so that it does not reach more than $0.8(\sim 0.6$ preferable $)$

9. Record $\mathrm{OD}_{600}$ for all (both OD should look between 0.5 and 0.6)

10. Centrifuge using the big benchtop centrifuge at $3000 \mathrm{xg}$ for 10 minutes

11. Remove the supernatant and add $5 \mathrm{ml}$ cold PBS. Vortex mix.

12. Repeat step 12 two more times and make sure the cells were washed properly so that no traces of BSM left in the 1.5\% NM-BSM tube. If you still see frothing, wash one more time.

13. Re-suspend cells in $700 \mu \mathrm{L} \mathrm{N}$-minimal salts buffered at pH 7.0 (No Mg added, or just salt mixture buffered at $\mathrm{pH} 7.0$ ).

14. Read the OD of both again and adjust the OD of $0 \%$ NM-BSM OD to 0.600 and $1.5 \%$ NM-BSM OD to 0.800 respectively with N-minimal salts buffered at $\mathrm{pH} 7.0$

15. Transfer $30 \mu \mathrm{L}$ of each into $2 \mathrm{ml}$ of $\mathrm{N}$-minimal salts buffered at $\mathrm{pH} 7.0$

16. Mix $100 \mu \mathrm{L}$ of each with $100 \mu \mathrm{L}$ of PBS.

17. Prepare 10-fold dilution in PBS up to $10^{-3}$ and plate out on LB agar to count bacteria the next day to confirm CFU/ml. (by mixing $20 \mu \mathrm{L}+180 \mu \mathrm{L}$ )

18. In a micro-titre plate, mix $100 \mu \mathrm{L}$ of each from step 16 and with $100 \mu \mathrm{L}$ of desired $2 \mathrm{X}$ concentration of $\mathrm{PMB}$

19. Incubate at $37^{\circ} \mathrm{C}$ in $5 \% \mathrm{CO}_{2}$ incubator for 1 hour.

20. Prepare 10-fold dilution in PBS up to $10^{-3}$ of each and plate out on LB agar to count the cells (CFU) the next day.

21. Use the already surface-dried LB plates, transfer $10 \mu \mathrm{L}$ onto LB plate and do track plating. Make sure all of them dry on the surface immediately. This is critical for PMB treated preparations. If remains unabsorbed into the media, PMB keeps acting on the cells. (If you use spot culture. Use dried plates and make sure the $10 \mu \mathrm{L}$ transferred onto LB dries out immediately, you can keep lid open in hood)

22. Incubate all the plates at $37^{\circ} \mathrm{C} 0 / \mathrm{N}$

Day 3 
23. Count the $\mathrm{CFU}$, express in $\mathrm{CFU} / \mathrm{ml}$ and calculate survival \%

24. The percent survival is calculated as follows: (CFU of polymyxin B-treated count/CFU of PBS-treated count)

\section{B) Killing assay protocol for $100 \mathrm{uM} \mathrm{Fe}^{3+}$ condition}

To assess the \% survival of EHEC 86-24 to polymyxin B ( $2 \mathrm{ug} / \mathrm{ml})$ induced under Nminimal medium (NM) with high $\mathrm{Fe}^{3+}\left(100 \mathrm{uM} \mathrm{FeSO}_{4}\right)$ and neutral $\mathrm{pH}+0 \mathrm{Fe}^{3+}$ and $\mathrm{NM}$ with high $\mathrm{Mg}$ and neutral $\mathrm{pH}$.

Day 1

$\mathrm{O} / \mathrm{N}$ culture

1. Prepare $1 \mathrm{mM} \mathrm{FeSO}_{4}$ solution and filter sterilize using $0.22 \mu \mathrm{m}$ membrane filter and syringe.

2. Prepare overnight samples of untreated and $100 \mathrm{uM} \mathrm{FeSO}_{4}$ treated cultures using a total volume of $5 \mathrm{~mL}$ in $10 \mathrm{~mL}$ round bottom culture tubes

a. Untreated $\rightarrow$ Prepare $5 \mathrm{ml} \mathrm{NM}$ with high $\mathrm{Mg}$ buffered at $\mathrm{pH}$ 7.0.

b. $100 \mathrm{uM} \mathrm{FeSO}_{4}$ treated $\rightarrow$ Prepare $5 \mathrm{ml} 100 \mathrm{uM} \mathrm{FeSO}_{4} .100 \mathrm{uM} \mathrm{FeSO}_{4}$ in $\mathrm{NM}$ with high $\mathrm{Mg}$ buffered at neutral $\mathrm{pH}$ and mix well (4.5 $\mathrm{ml} \mathrm{NM}$ and 0.5 $\mathrm{ml} 1 \mathrm{mM} \mathrm{FeSO}$ )

3. Inoculate a single colony from recent EHEC 86-24 plate.

4. Incubate at $37^{\circ} \mathrm{C} \mathrm{O} / \mathrm{N}$ on a shaker.

Day 2

5. Read $\mathrm{OD}_{600}$ of overnight cultures.

6. Repeat \#1, 2 to prepare media for subcultures with a total volume of $5 \mathrm{~mL}$ in 10 $\mathrm{mL}$ round bottom culture tubes. 
7. Inoculate $0 \mathrm{mM} \mathrm{FeSO}_{4}-\mathrm{NM}$ and $100 \mathrm{uM} \mathrm{FeSO}_{4}-\mathrm{NM}$ tubes with respective cultures $60 \mu \mathrm{L}$ from the $\mathrm{O} / \mathrm{N}$ culture.

8. Incubate at $37^{\circ} \mathrm{C}$ on a shaker for $3-4$ hours and monitor OD so that it does not reach more than $0.8(\sim 0.6$ preferable $)$

9. Record $\mathrm{OD}_{600}$ for all (both OD should look between 0.5 and 0.6 )

10. Centrifuge using the big benchtop centrifuge at $3000 \mathrm{xg}$ for 10 minutes

11. Remove the supernatant and add $5 \mathrm{ml}$ cold PBS. Vortex mix.

12. Repeat step 12 two more times and make sure the cells were washed properly so that no traces of Fe left in the NM-Fe tube. If you still see brown precipitates, wash one more time.

13. Re-suspend cells in $700 \mu \mathrm{L} \mathrm{N}$-minimal salts buffered at $\mathrm{pH} 7.0$ (No Mg added, or just salt mixture buffered at $\mathrm{pH} 7.0$ ).

14. Read the OD of both again and adjust the OD of both 0.600 with N-minimal salts buffered at $\mathrm{pH} 7.0$

15. Transfer $30 \mu \mathrm{L}$ of each into $2 \mathrm{ml}$ of $\mathrm{N}$-minimal salts buffered at $\mathrm{pH} 7.0$

16. Mix $100 \mu \mathrm{L}$ of each with $100 \mu \mathrm{L}$ of PBS.

17. Prepare 10 -fold dilution in PBS up to $10^{-3}$ and plate out on LB agar to count bacteria the next day to confirm $\mathrm{CFU} / \mathrm{ml}$. (by mixing $20 \mu \mathrm{L}+180 \mu \mathrm{L}$ )

18. In a micro-titre plate, mix $100 \mu \mathrm{L}$ of each from step 16 and with $100 \mu \mathrm{L}$ of desired $2 \mathrm{X}$ concentration of $\mathrm{PMB}$

19. Incubate at $37^{\circ} \mathrm{C}$ in $5 \% \mathrm{CO}_{2}$ incubator for 1 hour.

20. Prepare 10-fold dilution in PBS up to $10^{-3}$ of each and plate out on LB agar to count the cells (CFU) the next day.

21 . Use the already surface-dried LB plates, transfer $10 \mu \mathrm{L}$ onto LB plate and do track plating. Make sure all of them dry on the surface immediately. This is critical for PMB treated preparations. If remains unabsorbed into the media, PMB keeps acting on the cells. (If you use spot culture. Use dried plates and make sure the $10 \mu \mathrm{L}$ transferred onto LB dries out immediately, you can keep lid open in hood)

22. Incubate all the plates at $37^{\circ} \mathrm{C} 0 / \mathrm{N}$ 
Day 3

23. Count the CFU, express in CFU/ml and calculate survival $\%$

24. The percent survival is calculated as follows: (CFU of polymyxin B-treated count/CFU of PBS-treated count)

\section{C) Killing assay protocol for mildly low pH (pH 5.8) condition}

To assess the \% survival of EHEC 86-24 to polymyxin B $(2 \mathrm{ug} / \mathrm{ml})$ induced under Nminimal medium (NM) high $\mathrm{Mg}$ with low $\mathrm{pH}(\mathrm{pH}$ 5.8) and $\mathrm{NM}$ neutral $\mathrm{pH}$ with high $\mathrm{Mg}$.

Day 1

$\mathrm{O} / \mathrm{N}$ culture

1. Prepare overnight samples of neutral $\mathrm{pH}$ and low $\mathrm{pH}$ cultures using a total volume of $5 \mathrm{~mL}$ in $10 \mathrm{~mL}$ round bottom culture tubes

a. Neutral $\mathrm{pH} \rightarrow$ Prepare $5 \mathrm{ml} \mathrm{NM}$ with high $\mathrm{Mg}$ buffered at $\mathrm{pH} 7.0$

b. Mildly low $\mathrm{pH} \rightarrow$ Prepare $5 \mathrm{ml}$ low $\mathrm{pH}(\mathrm{pH} 5.8)$.

2. Inoculate a single colony from recent EHEC 86-24 plate.

3. Incubate at $37^{\circ} \mathrm{C} \mathrm{O} / \mathrm{N}$ on a shaker.

Day 2

4. Read $\mathrm{OD}_{600}$ of overnight cultures.

5. Repeat $\# 1,2$ to prepare media for subcultures with a total volume of $5 \mathrm{~mL}$ in 10 $\mathrm{mL}$ round bottom culture tubes.

6. Inoculate neutral $\mathrm{pH} \mathrm{NM}$ and low $\mathrm{pH}$ NM tubes with respective cultures $60 \mu \mathrm{L}$ from the $\mathrm{O} / \mathrm{N}$ culture.

7. Incubate at $37^{\circ} \mathrm{C}$ on a shaker for $3-4$ hours and monitor OD so that it does not reach more than $0.8(\sim 0.6$ preferable $)$ 
8. Record $\mathrm{OD}_{600}$ for all (both OD should look between 0.5 and 0.6 )

9. Centrifuge using the big benchtop centrifuge at $3000 \mathrm{xg}$ for 10 minutes

10. Remove the supernatant and add $5 \mathrm{ml}$ cold PBS. Vortex mix.

11. Repeat step 12 two more times and make sure the cells were washed properly.

12. Re-suspend cells in $700 \mu \mathrm{L} \mathrm{N}$-minimal salts buffered at $\mathrm{pH} 7.0$ (No Mg added, or just salt mixture buffered at $\mathrm{pH} 7.0$ ).

13. Read the OD of both again and adjust the OD of both 0.600 with $\mathrm{N}$-minimal salts buffered at $\mathrm{pH} 7.0$

14. Transfer $30 \mu \mathrm{L}$ of each into $2 \mathrm{ml}$ of $\mathrm{N}$-minimal salts buffered at $\mathrm{pH} 7.0$

15. Mix $100 \mu \mathrm{L}$ of each with $100 \mu \mathrm{L}$ of PBS.

16. Prepare 10 -fold dilution in PBS up to $10^{-3}$ and plate out on LB agar to count bacteria the next day to confirm CFU/ml. (by mixing $20 \mu \mathrm{L}+180 \mu \mathrm{L}$ )

17. In a micro-titre plate, mix $100 \mu \mathrm{L}$ of each from step 16 and with $100 \mu \mathrm{L}$ of desired $2 \mathrm{X}$ concentration of $\mathrm{PMB}$

18. Incubate at $37^{\circ} \mathrm{C}$ in $5 \% \mathrm{CO}_{2}$ incubator for 1 hour.

19. Prepare 10-fold dilution in PBS up to $10^{-3}$ of each and plate out on LB agar to count the cells (CFU) the next day.

20 . Use the already surface-dried LB plates, transfer $10 \mu \mathrm{L}$ onto LB plate and do track plating. Make sure all of them dry on the surface immediately. This is critical for PMB treated preparations. If remains unabsorbed into the media, PMB keeps acting on the cells. (If you use spot culture. Use dried plates and make sure the $10 \mu \mathrm{L}$ transferred onto LB dries out immediately, you can keep lid open in hood)

21. Incubate all the plates at $37^{\circ} \mathrm{C} \mathrm{O} / \mathrm{N}$

Day 3

22. Count the $\mathrm{CFU}$, express in $\mathrm{CFU} / \mathrm{ml}$ and calculate survival \%

23. The percent survival is calculated as follows: (CFU of polymyxin B-treated count/CFU of PBS-treated count) 


\section{D) $p m r D$-gfp promotor reporter assays}

1. Overnight cultures of $p m r D$ reporter strains (carrying $g f p$ under $p m r D$ promoter in the TOPO plasmid) and $p m r D$ control strain (carrying only TOPO plasmid) were centrifuged, washed, and resuspended in respective medium (low/high $\mathrm{Mg}^{+2}$ with or without BSM or $\mathrm{Fe}^{3+}$ ) and adjusted to 0.1 OD600.

2. $200 \mu 1$ of each cell suspension was immediately transferred into a 96-well plate and the cultures were grown in a Synergy HTX fluorescent plate reader (Biotek) at $37^{\circ} \mathrm{C}$ under continuous shaking mode.

3. Cultures were grown in a Synergy HTX Multi-Mode Plate Reader (Biotek) at $37^{\circ} \mathrm{C}$ under continuous shaking.

4. Measure absorbency ( $\mathrm{OD}_{600} \mathrm{~nm}$ ) and fluorescence (using a 485/20 nm excitation filter and a 528/20 nm emission filter) were monitored every $15 \mathrm{~min}$ for $16 \mathrm{~h}$.

5. The GFP fluorescence and the corresponding $\mathrm{OD}_{600}$ readings were retrieved from the machine and divided to generate the normalized ratio value of relative fluorescence units $(\mathrm{RFU}) / \mathrm{OD}_{600}$ as mentioned in methodology section.

6. The GFP fluorescence values were then adjusted for background by subtracting the normalized ratio value obtained for the corresponding control strain.

7. Fluorescence data were calculated as relative fluorescent units (RFU) per $\mathrm{OD}_{600}$ of each well as mentioned in methodology section.

8. Experiments were performed with three independent cultures, and the average fluorescence and standard deviations were calculated on these triplicates. 


\section{References}

Avery LM, Williams AP, Killham K, Jones DL. 2008. Survival of Escherichia coli, O157 :

H7 in waters from lakes, rivers, puddles and animal-drinking troughs. Sci Total Environ 389: 378-385.

Begley M, Gahan CGM, Hill C. 2005. The interaction between bacteria and bile. FEMS Microbiol Rev 29: 625-651.

Bevins CL, Salzman NH. 2011. Paneth cells, antimicrobial peptides and maintenance of intestinal homeostasis. Nat Rev Microbiol 9: 356-368.

CDC. 2016. Escherichia coli (E. coli). Natl Cent Emerg Zoonotic Infect Dis 2. https://www.cdc.gov/ecoli/pdfs/cdc-e.-coli-factsheet.pdf

Cheng, C., Dong, Z., Han, X., Sun, J., Wang, H., Jiang, L., ... Song, H. (2017). Listeria monocytogenes 10403S arginine repressor ArgR finely tunes arginine metabolism regulation under acidic conditions. Frontiers in Microbiology.

Chen HD, Groisman EA. 2013. The biology of the PmrA/PmrB two-component system: the major regulator of lipopolysaccharide modifications. Annu Rev Microbiol 67: 83112.

Choi J, Groisman EA. 2017. Activation of master virulence regulator PhoP in acidic $\mathrm{pH}$ requires the Salmonella -specific protein UgtL. Sci Signal 6284: 1-10. 
Crim SM, Iwamoto M, Huang JY, Griffin PM, Gilliss D, Cronquist AB, Cartter M, TobinD’Angelo M, Blythe D, Smith K, et al. 2013. Incidence and trends of infection with pathogens transmitted commonly through food - foodborne diseases active surveillance network, 10 U.S. sites, 1996-2012. MMWR Morb Mortal Wkly Rep 62: $283-287$.

Croxen MA, Law RJ, Scholz R, Keeney KM, Wlodarska M, Finlay BB. 2013. Recent advances in understanding enteric pathogenic Escherichia coli. Clin Microbiol Rev.

Datsenko KA, Wanner BL. 2000. One-step inactivation of chromosomal genes in Escherichia coli K-12 using PCR products. Proc Natl Acad Sci U S A 97: 6640-5.

De Smet K, Contreras R. 2005. Human antimicrobial peptides: Defensins, cathelicidins and histatins. Biotechnol Lett 27: 1337-1347.

Doss M, White MR, Tecle T, Hartshorn KL. 2010. Human defensins and LL-37 in mucosal immunity. J Leukoc Biol 87: 79-92.

Eguchi Y, Ishii E, Yamane M, Utsumi R. 2012. The connector SafA interacts with the multi-sensing domain of PhoQ in Escherichia coli. Mol Microbiol.

Fabisiak A, Murawska N, Fichna J. 2016. LL-37: Cathelicidin-related antimicrobial peptide with pleiotropic activity. Pharmacol Reports.

Gorden J, Small PL. 1993. Acid resistance in enteric bacteria. Infect Immun.

Gunn JS. 2001. Bacterial modification of LPS and resistance to antimicrobial peptides. $J$ 


\section{Endotoxin Res.}

Gunn JS. 2000. Mechanisms of bacterial resistance and response to bile. Microbes Infect 2: $907-913$.

Hancock REW, Diamond G. 2000. The role of cationic antimicrobial peptides in innate host defences. Trends Microbiol 8: 402-410.

House B, Kus J V., Prayitno N, Mair R, Que L, Chingcuanco F, Gannon V, Cvitkovitch DG, Foster DB. 2009. Acid-stress-induced changes in enterohaemorrhagic Escherichia coli O157: H7 virulence. Microbiology 155: 2907-2918.

Jenkins SG, Schuetz AN. 2012. Current concepts in laboratory testing to guide antimicrobial therapy. In Mayo Clinic Proceedings.

Johannes L, Römer W. 2010. Shiga toxins — from cell biology to biomedical applications. Nat Rev Microbiol 8: 105-116.

Jung K, Fried L, Behr S, Heermann R. 2012. Histidine kinases and response regulators in networks. Curr Opin Microbiol.

Kato A, Groisman EA. 2004. Connecting two-component regulatory systems by a protein that protects a response regulator from dephosphorylation by its cognate sensor. Genes Dev 18: 2302-2313.

Kato A, Latifi T, Groisman EA. 2003. Closing the loop: the PmrA/PmrB two-component system negatively controls expression of its posttranscriptional activator PmrD. Proc 
Natl Acad Sci U S A.

Kato A, Mitrophanov AY, Groisman EA. 2007. A connector of two-component regulatory systems promotes signal amplification and persistence of expression. Proc Natl Acad Sci.

Kim SH, Jia W, Parreira VR, Bishop RE, Gyles CL. 2006. Phosphoethanolamine substitution in the lipid A of Escherichia coli O157: H7 and its association with PmrC. Microbiology 152: 657-666.

Kiranmayi CB, Krishnaiah N, Mallika EN. 2010. Escherichia coli O157: H7 - An Emerging Pathogen in foods of Animal Origin. Vet World 3: 382-389.

Kus J V., Gebremedhin A, Dang V, Tran SL, Serbanescu A, Foster DB. 2011. Bile salts induce resistance to polymyxin in enterohemorrhagic Escherichia coli O157:H7. $J$ Bacteriol 193: 4509-4515.

Le CF, Fang CM, Sekaran SD. 2017. Intracellular targeting mechanisms by antimicrobial peptides. Antimicrob Agents Chemother.

Lee H, Hsu FF, Turk J, Groisman EA. 2004. The PmrA-regulated $p m r C$ gene mediates phosphoethanolamine modification of lipid A and polymyxin resistance in Salmonella enterica. J Bacteriol 186: 4124-4133.

Lim JY, Yoon JW, Hovde CJ. 2010. A brief overview of Escherichia coli O157:H7 and its plasmid O157. J Microbiol Biotechnol. 
Lin Z, Cai X, Chen M, Ye L, Wu Y, Wang X, Lv Z, Shang Y, Qu D. 2018. Virulence and stress responses of Shigella flexneri regulated by PhoP/PhoQ. Front Microbiol.

Luo SC, Lou YC, Cheng HY, Pan YR, Peng HL, Chen C. 2010. Solution structure and phospho-PmrA recognition mode of PmrD from Klebsiella pneumoniae. J Struct Biol 172: $319-330$.

Luo SC, Lou YC, Rajasekaran M, Chang YW, Hsiao CD, Chen C. 2013. Structural basis of a physical blockage mechanism for the interaction of response regulator PmrA with connector protein PmrD from Klebsiella pneumoniae. J Biol Chem 288: 2555125561.

Matsuura M. 2013. Structural modifications of bacterial lipopolysaccharide that facilitate gram-negative bacteria evasion of host innate immunity. Front Immunol.

Mayer CL, Leibowitz CS, Kurosawa S, Stearns-Kurosawa DJ. 2012. Shiga toxins and the pathophysiology of hemolytic uremic syndrome in humans and animals. Toxins (Basel) 4: 1261-1287.

Merritt ME, Donaldson JR. 2009. Effect of bile salts on the DNA and membrane integrity of enteric bacteria. J Med Microbiol.

Mitrophanov AY, Jewett MW, Hadley TJ, Groisman EA. 2008. Evolution and dynamics of regulatory architectures controlling polymyxin B resistance in enteric bacteria. PLoS Genet 4. 
Nguyen Y, Sperandio V. 2012. Enterohemorrhagic E. coli (EHEC) pathogenesis. Front Cell Infect Microbiol.

Ohl ME, Miller SI. 2001. Salmonella: A Model for Bacterial Pathogenesis. Annu Rev Med.

Omardien S, Brul S, Zaat SAJ. 2016. Antimicrobial Activity of Cationic Antimicrobial Peptides against Gram-Positives: Current Progress Made in Understanding the Mode of Action and the Response of Bacteria. Front Cell Dev Biol.

Page A V., Liles WC. 2013. Enterohemorrhagic Escherichia coli Infections and the Hemolytic-Uremic Syndrome. Med Clin North Am 97: 681-695. http://www.sciencedirect.com/science/article/pii/S0025712513000576.

Perez, J. C., \& Groisman, E. A. (2007). Acid pH activation of the PmrA/PmrB twocomponent regulatory system of Salmonella enterica. Molecular Microbiology, 63(1), 283-293. https://doi.org/10.1111/j.1365-2958.2006.05512.x

Pazgier M, Ericksen B, Ling M, Toth E, Shi J, Li X, Galliher-Beckley A, Lan L, Zou G, Zhan C, et al. 2013. Structural and functional analysis of the pro-domain of human cathelicidin, LL-37. Biochemistry 52: 1547-1558.

Prost LR, Daley ME, Le Sage V, Bader MW, Le Moual H, Klevit RE, Miller SI. 2007. Activation of the Bacterial Sensor Kinase PhoQ by Acidic pH. Mol Cell.

Prouty AM, Brodsky IE, Falkow S, Gunn JS. 2004. Bile-salt-mediated induction of antimicrobial and bile resistance in Salmonella typhimurium. Microbiology 150: 775- 
783.

Raetz CRH, Reynolds CM, Trent MS, Bishop RE. 2007. Lipid A Modification Systems in Gram-Negative Bacteria. Annu Rev Biochem.

Rubin EJ, Herrera CM, Crofts AA, Trent MS. 2015. PmrD is required for modifications to Escherichia coli endotoxin that promote antimicrobial resistance. Antimicrob Agents Chemother 59: 2051-2061.

Safdar N, Said A, Gangnon RE, Maki DG. 2002. Risk of hemolytic uremic syndrome after antibiotic treatment of Escherichia coli $\mathrm{O} 157: \mathrm{H} 7$ enteritis: a meta-analysis. JAMA 288: 996-1001.

Sankaran-Walters S, Hart R, Dills C. 2017. Guardians of the gut: Enteric defensins. Front Microbiol 8: 1-8.

Schneider JJ, Unholzer A, Schaller M, Schäfer-Korting M, Korting HC. 2005. Human defensins. J Mol Med.

Simpson RJ, Peters TJ. 1990. Forms of soluble iron in mouse stomach and duodenal lumen: significance for mucosal uptake. Br J Nutr.

Sivieri K, Bassan J, Peixoto G, Monti R. 2017. Gut microbiota and antimicrobial peptides. Curr Opin Food Sci.

Smith JL, Fratamico PM, Gunther NW. 2014. Shiga toxin-producing Escherichia coli. Adv Appl Microbiol. 
Sockett P, Goebel SE, Varela NP, Guthrie A, Wilson J, Guilbault LA, Clark WF. 2014. Verotoxigenic Escherichia coli: Costs of Illness in Canada, Including Long-Term Health Outcomes. J Food Prot 77: 216-226.

Sorg JA, Sonenshein AL. 2008. Bile salts and glycine as cogerminants for Clostridium difficile spores. $J$ Bacteriol.

Van Velkinburgh JC, Gunn JS. 1999. PhoP-PhoQ-regulated loci are required for enhanced bile resistance in Salmonella spp. Infect Immun 67: 1614-1622.

Vanaja SK, Jandhyala DM, Mallick EM, Leong JM, Balasubramanian S. 2013. Enterohemorrhagic and other Shigatoxin-producing Escherichia coli. In Escherichia coli: Pathotypes and Principles of Pathogenesis: Second Edition.

Winfield MD, Groisman E a. 2004. Phenotypic differences between Salmonella and Escherichia coli resulting from the disparate regulation of homologous genes. Proc Natl Acad Sci U S A 101: 17162-7.

Xhindoli D, Pacor S, Benincasa M, Scocchi M, Gennaro R, Tossi A. 2016. The human cathelicidin LL-37 - A pore-forming antibacterial peptide and host-cell modulator. Biochim Biophys Acta - Biomembr 1858: 546-566. http://dx.doi.org/10.1016/j.bbamem.2015.11.003.

Yi H, Hu W, Chen S, Lu Z, Wang Y. 2017. Cathelicidin-WA Improves Intestinal Epithelial Barrier Function and Enhances Host Defense against Enterohemorrhagic Escherichia coli O157:H7 Infection. J Immunol. 
Zhou Z, Ribeiro AA, Lin S, Cotter RJ, Miller SI, Raetz CRH. 2001. Lipid A modifications in polymyxin-resistant Salmonella typhimurium: PmrA-dependent 4-amino-4-deoxyL-arabinose, and phosphoethanolamine incorporation. J Biol Chem 276: 4311143121. 